\title{
Glial Domains and Nerve Fiber Patterns in the Fish Retinotectal Pathway
}

\author{
Alison Maggs and John Scholes \\ MRC Cell Biophysics Unit, King's College London, London WC2B 5RL, England
}

\begin{abstract}
Optic nerve fibers run parallel from the retina as far as the optic tract in fish, then suddenly criss-cross into a new pattern matching the tectal map. This change coincides with a unique demarcation between two astroglial territories in the retinotectal pathway, located where the optic chiasm occurs in other vertebrates, which we defined using antibodies directed against intermediate filaments (IF).

We found that astroglia in optic nerve territory express an $M_{r}$ 56,000 IF polypeptide, band 3, which we identify as the fish equivalent of vimentin in mammals. These astrocytic cells lack glial fibrillary acidic protein (GFAP; cf. Dahl and Bignami, 1973). Conversely, glia in brain territory, that is, in the optic tract and elsewhere in the CNS, lack the fish vimentin, but express GFAP.

By electron microscopy, we obtained evidence that new retinal axons extend swiftly through the growing optic nerve, where they are tightly shepherded into a narrow track by newly differentiating glial cells, positive for the fish vimentin. In the GFAP-positive glial territory of the optic tract, by contrast, growing axons are slowed down and probably branch. We suggest that this allows them to fasciculate accurately with older fibers and thereby propagate a tectotopic pattern established by pioneer axons in the embryo.
\end{abstract}

Contrasting with rapid and somewhat chaotic axonal outgrowth in the embryonic visual pathway of mammals and birds (Lund et al., 1980; Rager, 1980; Rakic and Riley, 1983), continued slow growth in adult fish leads to the formation of exceptionally orderly optic fiber patterns. Axons become arranged chronologically, preserving neighbor relations, but in patterns reflecting different programs of growth in various parts of the retinotectal pathway (Bunt and Horder, 1977; Easter et al., 1984; Rusoff, 1984; Rusoff and Easter, 1980; Scholes, 1979; Stuermer and Easter, 1984). This orderly packaging of the visual pathway in fish makes it possible to define the navigational task facing retinal axons growing to the optic tectum. Whereas they run smoothly parallel most of the way, the axons transiently interweave through a monocular fiber crossover within each optic nerve, where it joins the optic tract, assorting into a new array that matches the tectal map, as first noted by Lubsen in 1921. In fish, the optic nerves usually cross bodily at the midline, managing to bypass the normal interwoven type of optic chiasm found in other vertebrates. This simplification reveals the internal monocular fiber-crossing as a separate feature in the visual

\footnotetext{
Received Apr. 10, 1985; revised July 15, 1985; accepted July 17, 1985

We thank B. B. Boycott, P. A. M. Eagles, D. Fekete, R. D. Fernald, and R. Karam for their helpful criticisms of the manuscript. We are grateful to B. Anderton for discussions, and to him, P. A. M. Eagles, R. Mirsky, M. C. Raff, and C. Thomas for gifts of antibodies, as detailed in Methods. We also thank R. Rao for mammalian intermediate filament preparations.

Correspondence should be addressed to John Scholes, MRC Cell Biophysics Unit, King's College London, 26-29 Drury Lane, London WC2B 5RL, England. Copyright (C) 1986 Society for Neuroscience $0270-6474 / 86 / 020424-15 \$ 02.00 / 0$
}

pathway, although with a somewhat similar criss-crossed histological appearance. We believe, on topological grounds, that it constitutes a basic part of the design of the vertebrate retinotectal pathway, yet to be found in some guise in other vertebrate groups (Scholes, 1981a, b).

The monocular crossover must result from some change in the tracking hehavior of growing fibers arriving at the optic tract, and this raises various related questions. What promotes reassortment at this level in the visual pathway, and what guidance cues are used at this distance from the tectum? What is the relationship between the monocular fiber-crossing and the optic chiasm in other vertebrates?

To approach these questions, we compared the cytology of the optic nerve and tract; we show here that their astrocytes have different glial intermediate filaments (IF). We found that the fish optic nerve astroglia express a vimentin-like (Franke et al., 1978) IF polypeptide exclusively, and lack (cf. Dahl and Bignami, 1973) GFAP, the glial fibrillary acidic protein (Eng et al., 1971). Conversely, astroglia elsewhere in the fish brain and spinal cord have GFAP, but completely lack the vimentin-like IF found in the optic nerve. To relate these differences to the optic fiber patterns, we examined growing axons by EM and found clear evidence that growth cones extend swiftly through vimentin astroglial territory in the optic nerve, but are drastically slowed down among the GFAP-containing astroglia of the optic tract.

These findings are of interest in two general contexts. First, they could have some bearing on why, in contrast with lower vertebrates, CNS regenerative capacity in mammals becomes restricted shortly after birth (cf. Kalil and Reh, 1979), at around the time when glia differentiate terminally. Glial precursor cells of the embryo neuroepithelium in mammals and birds, which form template surfaces for axonal outgrowth (Silver and Rutishauser, 1984; Singer et al., 1979), express vimentin exclusively (Schnitzer et al., 1981; Tapscott et al., 1981) and only switch on GFAP postnatally in mammals, when myelination also ensues (Dahl, 1981; Dahl et al., 1981). This is when capacity for axonal regeneration is lost, so it may be more than a coincidence that the adult fish optic nerve contains vimentin-based astroglia, and can quickly regenerate severed axons (cf. Berry, 1979; Reier et al., 1983).

Second, the findings may illuminate general mechanisms of development in the visual pathway. In his classic experiments, R. W. Sperry $(1943,1963)$ surgically mismatched the eye and brain to show that active recognition processes guide optic fibers to their correct terminal loci in the optic tectum. The monocular fiber-crossing shows that the array of retinal fibers in the optic nerve is mismatched with the tectum in any case. This indicates that neural recogition mechanisms must operate en route to the brain, not just in the tectum. The growing fibers must be able to discriminate one another on some basis related to retinal position, as recently assayed in vitro by Bonhoeffer and Huf (1985). But why should new axons apparently change prefer- 
ences on entering the optic tract? We suggest that their growth response to the tract boundary allows exploration of preexisting fibers, enabling selective fasciculation and propagation of a wiring pattern established in the embryo when pioneer axons first connect with the tectal rudiment (cf. Holt, 1984). Similar responses at the optic chiasm in other vertebrates could underlie binocular decussation and segregate the different afferent-fiber maps, as in mammals (Torrealba et al., 1982; Walsh and Guillery, 1984).

\section{Materials and Methods}

\section{Animals}

We used material from the African cichlid fish, Tilapia nilotica, to prepare antibodies; this animal, along with the South American cichlid, Cichlasoma meeki, was used for the biochemical and structural work. Minor species differences, such as slight molecular weight variations, were noted but did not affect the conclusions.

\section{$S D S-P A G E$}

Samples of fish material for SDS-PAGE were dissected under 6-40× magnification into chilled Hank's solution, homogenized in the presence of $2 \%$ SDS and $1 \% \beta$-mercaptoethanol, and run on 5-15\% gradient gels using the Laemmli (1970) system. Molecular weights were estimated relative to myosin, phosphorylase $\mathrm{B}$, glutamate dehydrogense, actin, and the mammalian neurofilament triplet. Partial proteolytic fingerprints were made with papain, following Cleveland et al. (1975).

\section{Antibodies and immune assays}

Two rabbit antisera (Ab2 and Ab3) were raised against fish optic nerve bands 2 and 3 (Fig. 3) by immunization with protein samples eluted electrophoretically from excised SDS-gel bands. We also used antibodies against GFAP (Pruss, 1979), IF (Pruss et al., 1981), and vimentin (Hynes and Destree, 1978; Jacobs et al., 1982; Ramaekers et al., 1981; Virtanen et al., 1981). Immunoblots were made by modifications of the methods of Towbin et al. (1979) and Burnette (1981). Transfers were blocked with $2 \% \mathrm{BSA}$ and incubated with antibody solutions at room temperature, followed, in the case of the monoclonal reagents, with an amplification layer of rabbit anti-mouse $\operatorname{IgG}$ or IgM antiserum. The blots were incubated with ${ }^{125} \mathrm{I}-$ Staphylococcus protein A or ${ }^{125} \mathrm{I}-\mathrm{IgG}$ (Amersham) and exposed to Kodak X-Omat RP x-ray film. The antibody solutions contained $2 \% \mathrm{BSA}$ and azide in $0.9 \% \mathrm{NaCl} / 10 \mathrm{~mm}$, pH 7.4, Tris- $\mathrm{HCl}$ buffer throughout, and the first antibody dilutions were $\mathrm{Ab} 3$, 1:150; Ab2, 1:100; AbGFAP, 1:50 and MAbIF, 1:100 (Ab2, Ab3, and AbGFAP: antisera against bands 2 and 3 and GFAP; MAbIF: monoclonal antibody against IF).

For the immunofluorescence microscopy shown, unfixed frozen material was sectioned at $5-10 \mu \mathrm{m}$ onto gelatin-alum subbed slides and incubated for $20 \mathrm{~min}$ at room temperature, with antibody solutions in PBS with azide. Similar results were also obtained after solvent extraction or $0.1 \%$ paraformaldehyde fixation of the tissues or sections. First layers contained $2 \%$ BSA with $0.3 \%$ Triton X-100; washes used $1 \%$ Triton; and second and third layers were in PBS alone. Final layers were FITC goat anti-rabbit IgG antiserum (Nordic), absorbed overnight at $4^{\circ} \mathrm{C}$ against washed fish brain homogenate. First-layer dilutions were Ab3, 1:100; Ab2, 1:200; AbGFAP, 1:50; and MAbIF, 1:100. Preimmune sera were routinely tested alongside these antibodies.

\section{Conventional microscopy}

For light and electron microscopy, material was exposed in situ and irrigated for 5-15 min with chilled 5-7\% glutaraldehyde in $100 \mathrm{~mm} \mathrm{Na}$ cacodylate buffer, $\mathrm{pH} 7.3$, then dissected and fixed for a further 3-16 $\mathrm{hr}$ at $4^{\circ} \mathrm{C}$. The material was washed and post-fixed with $0.5 \% \mathrm{OsO}_{4}$ in buffer with $15-25 \%$ sucrose. Araldite sections were mounted on Formvar films on slot grids and stained conventionally with uranyl and lead salts.

\section{Results}

\section{Anatomical synopsis}

The plan of the retinotectal pathway in fish is unique in two respects. First, the optic nerves tend to form longitudinally fold-
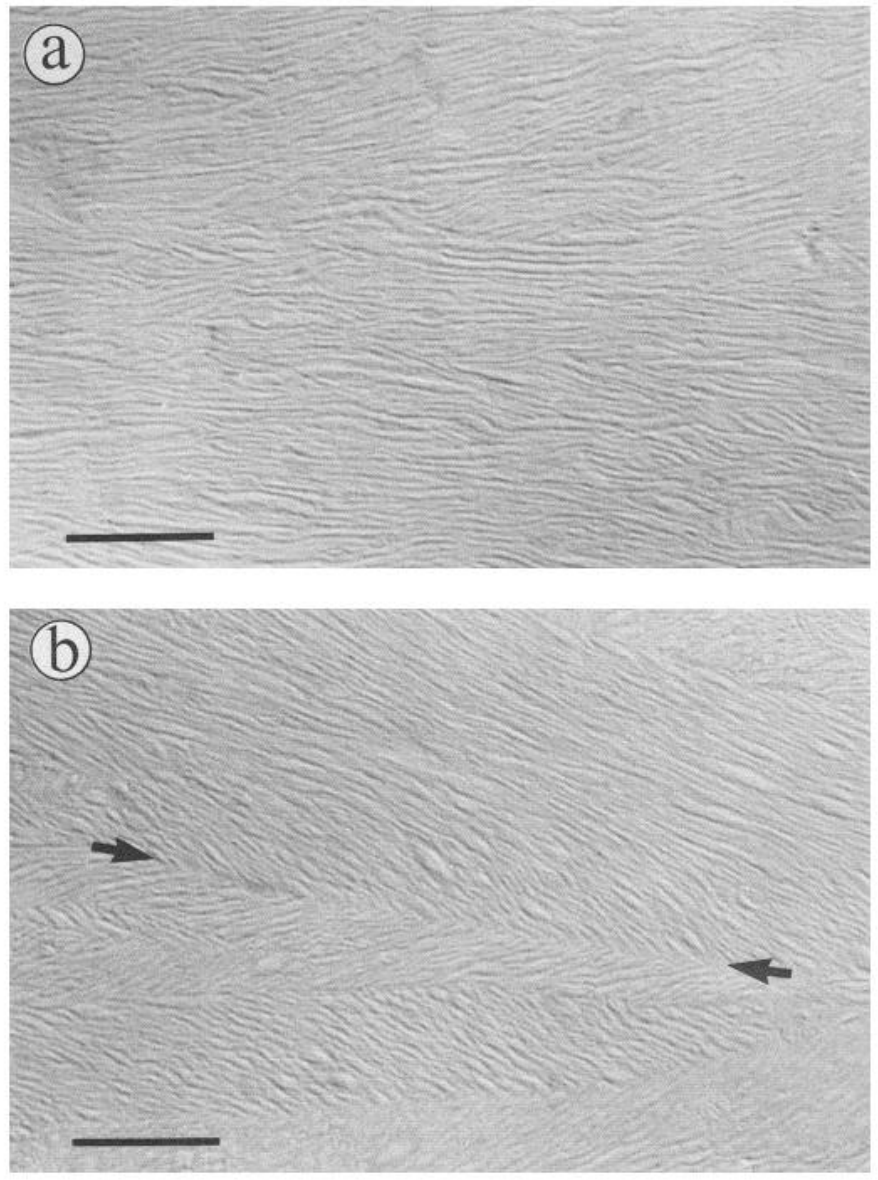

Figure 1. Optic nerve fibers run parallel through most of the fish visual pathway, but suddenly criss-cross as they approach the optic tract. These two micrographs are from nearby regions in the same $1 \mu \mathrm{m}$ LS of the visual pathway, viewed by Nomarski optics. $a$, Axons running parallel inside a fold of the ribbon at about the level indicated by the left-hand arrow in Fig. $2 a$, about $300 \mu \mathrm{m}$ from the tract. $b$, Nearer the brain, about $150 \mu \mathrm{m}$ from the optic tract and at the level of the right-hand arrow in Fig. $2 a$, axons have abruptly segregated into countercurrent bundles running between the ribbon surfaces (beyond the top and bottom of the micrograph) in the monocular retinotectal fiber-crossing (cf. Fig. 2). Arrowheads, A bundle interface. Scale bars, $25 \mu \mathrm{m}$.

ed ribbons. Secondly, they usually cross bodily at the midline (although certain fish do have interwoven optic chiasms; Schwassman, 1975), so that they join the brain contralaterally. Normally, in vertebrates, the optic nerves join the tracts at the midline, by interweaving through the optic chiasm embedded in brain tissue.

The axonal patterns formed at this level in fish have been outlined elsewhere (Scholes, 1979, 1981a), but we present here a new summary to help visualize (1) the histological appearance of the monocular fiber-crossing (see Fig. 1), (2) where the crossing is located relative to the glial boundary studied, between the nerve and tract (see Figs. 2 and 5), and (3) how it fits into the topology of the retinotectal pathway (Fig. 2), compared with that in vertebrates generally.

Retinal axons run parallel in the ribbon, as shown in the longitudinal section (LS) in Figure $1 a$, taken close to the tract within one of the folds of the nerve at the level indicated by the left arrow in Figure $2 a$. As described previously (Scholes, 1979), new fibers from the retinal margin are added retinotopically to a narrow track at one edge of the ribbon (u in Fig. $2 a$ ), so that the map of the retinal clockface gets compressed between the two surfaces of this structure on leaving the retina, as shown in 


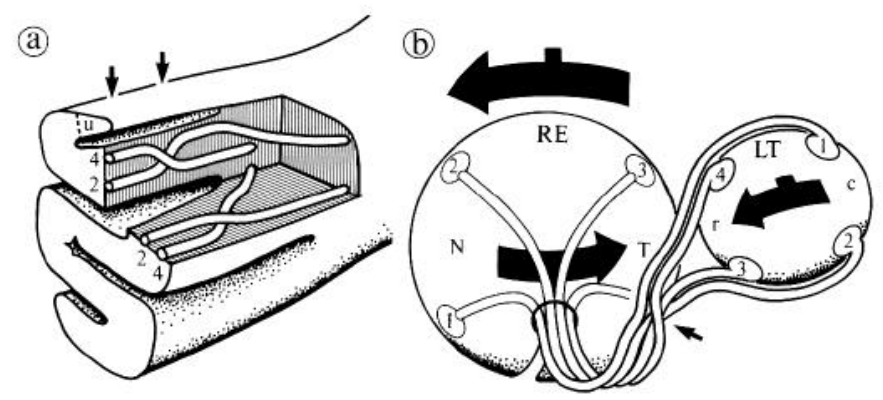

Figure 2. These diagrams explain the topography of the fiber reassortment at the optic tract boundary in fish. $a$, Semischematic diagram of the junction of the right ribbon optic nerve and the left tract, viewed as if dissected away from the brain, showing how retinal fibers ( 2 and 4 ; cf. Fig. $2 b$ ) cross, then decussate laterally and medially, to the tectal brachia. Arrows (left to right) locate Fig. 1, $a$ and $b$, respectively; $u$ is the growing edge of the ribbon, containing new fibers. $b$, Highly schematic diagram showing the right eye $(R E)$ and left tectum $(L T$, viewed from the animal's left). A large black arrow is imaged in the eye, and the diagram shows how it is mapped upright in the tectum. A cohort of new retinal fibers (1-4) arrives centrally via two piecewise reversals of their order, the first at the optic tract (small arrow). The second reversal is hidden in the tectal radiation pattern, an inverse of that in the retina. This can be seen as follows: if the fibers formed the same pattern on the tectum as in the retina, the map of loci $1-4$ would run anticlockwise, not clockwise as shown. Older retinal fibers (not shown) assort independently in separate age-related cohorts. $N$, Nasal; $T$, temporal; $r$, rostral; $c$, caudal.

Figure $2 b$. The fiber pattern becomes complicated just before the nerve joins the optic tract. Bundles of axons begin to exchange positions between the two surfaces of the ribbon in the last $100 \mu \mathrm{m}$ or so of the optic nerve, generating characteristic herringbone patterns. This is illustrated in Figure $1 b$, a micrograph from the same LS as in $a$, and in the same ribbon fold, but located about $150 \mu \mathrm{m}$ nearer the optic tract boundary at the level of the right arrow in Figure $2 a$. The outcome is that fibers arrive in the tract in a new tectotopic pattern, roughly matching the visual map in the optic tectum (Fig. $2 b$ ).

What is the significance of these surprising patterns? Figure $2 b$ shows schematically how they result in an upright tectal map, aligned with the opposite visual field (large black arrow). This could also be achieved by twisting the optic nerve bodily through $180^{\circ}$, compensating for image inversion in the eye, but fish (and presumably other vertebrates) use an alternative dual strategy. Successive cohorts of new fibers first interweave at the optic tract (small arrow, Fig. $2 b$ ), and then invest the tectal margin in an inverse of the spoke-like pattern leaving the retina (Fig. $2 b$ ). This piecewise reassortment exemplifies an equivalence well known in crystallographic symmetry, namely, that two mirror reversals through planes at right angles achieve a rotation through $180^{\circ}$ (cf., e.g., Buerger, 1978).

Axons also form interwoven bundles in the optic tract, but these patterns are distinct from the monocular fiber-crossing and relate to shape changes in the pathway. Thus, fibers sheer past one another, following the two folded surfaces of the ribbon as these fuse with the simple outline of the optic tract (Fig. 2a), and also segregate towards separate diencephalic and rectal targets (Presson et al., 1985). Whereas the optic fiber array becomes cemented into precise chronological patterns in the optic nerve and tectum, the tract is a more loosely organized structure. It forms an interface where axons match up different peripheral and central patterns of retinotopy and growth, and also assort to different central targets (cf. Torrealba et al., 1982).

\section{Glial cytoskeletons differ between optic nerve and tract}

The optic nerve is much more resilient mechanically than optic tract tissue, and we found that this difference is reflected by the

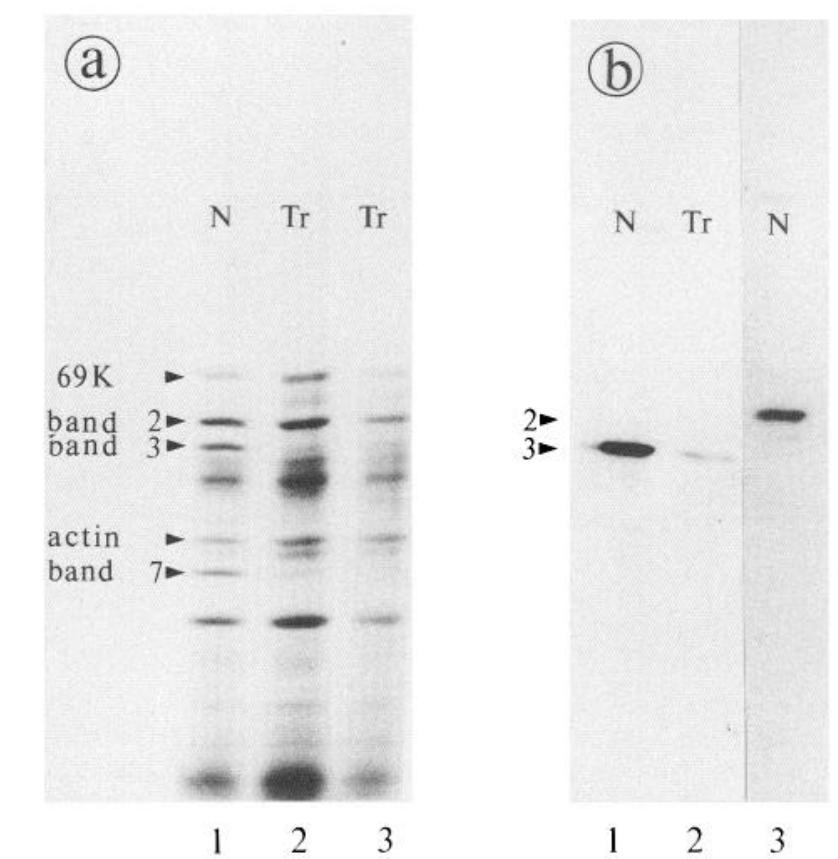

Figure 3. Two major polypeptides, bands 3 and 7 , are abundant in the optic nerve but sparse in the tract. $a$, SDS-PAGE of samples from either side of a cut through the junction of the fish optic nerve and tract (see Fig. 2a). Lane 1 is optic nerve $(N)$, and lanes 2 and 3 are tract $(T r)$ samples at different loadings. The unequal distribution of bands 3 and 7 , contrasting with that of other major bands (e.g., band 2, which is axonal; see Fig. 5 and text), shows that they must be of satellite cell origin. Molecular weights estimated as in Methods. $b$, Immunoblots showing the specificity of the antisera raised against bands 2 and 3 . Lanes 1 and 2 show that $\mathrm{Ab} 3$ is specific for band 3, reflecting the distribution of this protein in nerve $(N)$ and tract $(T r)$ gel lanes $(a)$. Lane 3 shows Ab2 specificity for band 2 in a blot of an optic nerve lane.

major polypeptides analyzed by SDS-PAGE. In Figure $3 a$, gel samples from tissue on either side of a cut through the nerve/ tract boundary show that a major optic nerve protein (band 3, lane $1, N$ ) is hardly present in the tract (lanes 2 and 3, Tr), meaning that it must be of satellite cell, not axonal, origin. Band 3 has an apparent molecular weight of 56,000 , and is cytoskeletal, that is, detergent-insoluble (Triton X-100 in neutral $50 \mathrm{~mm}$ Tris-HCl). Another cytoskeletal polypeptide shared this distribution (band 7, $M_{r} 38,000$; lane 1), but revealed no homology with band 3 in papain peptide maps (Cleveland et al., 1977).

To determine the origin of band 3 , we made rabbit antibodies against this protein, purified for immunization by elution from gel bands. We also made an antiserum against band 2, the other major optic nerve cytoskeletal protein, which we found to be axonal (see below). The immunoblots in Figure $3 b$ show that these two antisera, Ab2 and Ab3, are highly specific for their respective immunogen bands. By immunofluorescence, in frozen, unfixed sections, $\mathrm{Ab} 3$ reacted with two distinct components of CNS tissue: first, an astroglial network unique to the optic nerve, and, second, meningeal membranes and capillaries throughout the CNS.

In contrast with the remainder of the $\mathrm{CNS}$, the ribbon optic nerve is not penetrated by capillaries from the pia; but Ab3 labeled an extensive network of columnar astrocytic processes and their external endfeet (Fig. $4 a$ ). These astrocytic cells were easily distinguished from oligodendrocytes, the only other numerous endoneurial satellite cells, by their configuration, which was also visible by phase contrast (compare Fig. $4, c$ and $d$ ); they were distinguishable, as well, by the transverse orientation of their nuclei in the ribbon, orthogonal to the optic axons. In 

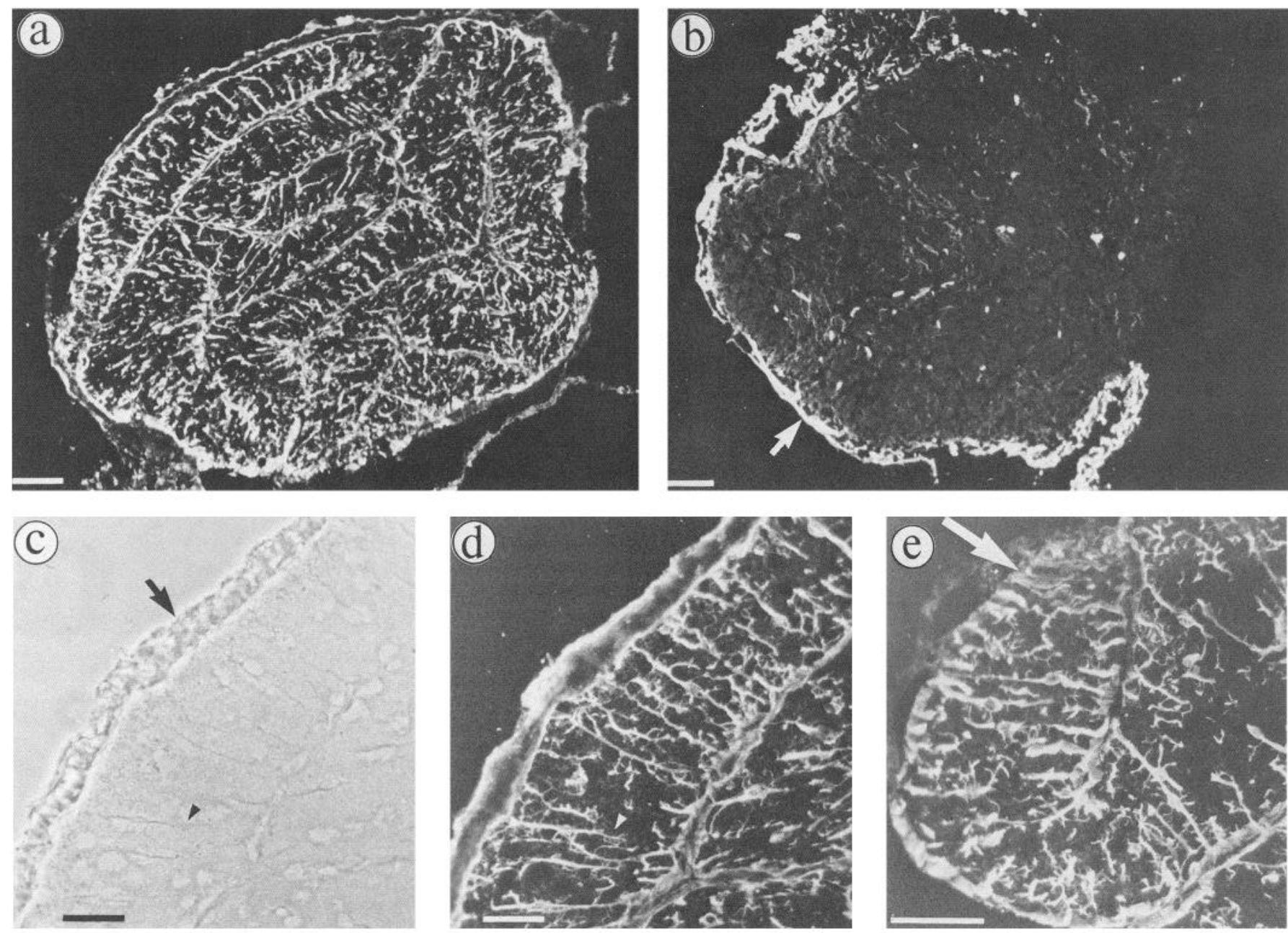

Figure 4. Band 3 is a cytoskeletal protein localized in astrocytes and glial progenitor cells in the fish optic nerve, but not in optic tract glia. $a$ and $b$, FITC-immunofluorescence using Ab3 on frozen, unfixed $5 \mu \mathrm{m}$ cross sections of the ribbon optic nerve and the tract, respectively. Astroglia, spanning the ribbon folds, are labeled in the nerve, but only the meningeal membrane (arrow), capillaries, and very sparse glia in the tract. Scale bars, $25 \mu \mathrm{m}$. $c$ and $d$, Phase-contrast and fluorescence micrographs, respectively, of an optic nerve CS, showing that Ab3 labels all major visible astrocytic profiles (e.g., arrowheads). Arrow, The optic nerve sheath. Scale bars, $25 \mu \mathrm{m}$. $e$, Cross section of the growing edge of the ribbon (arrow) labeled with $\mathrm{Ab} 3$, showing that differentiating glial progenitor cells in this part of the nerve (cf. Fig. 10a) also express band 3. Scale bar, $25 \mu \mathrm{m}$.

the optic tract, however, Ab3 revealed only occasional fine glial fibers (Fig. $4 b$ ), in addition to the meningeal membrane (arrow) and endoneurial capillaries. In the optic nerve, as shown in Figure $4 e$ (arrow), Ab3 also reacted with undifferentiated optic nerve satellite cells along the growing edge of the ribbon, which we identified as glial precursor cells by their appearance (see Fig. 1 $1 a$ ) and using $3 \mathrm{H}-\mathrm{TdR}$ autoradiography (unpublished observations). Compared with the astrocytic columns bridging the rest of the ribbon (Fig. 4, $c$ and $d$; Fig. 6a), their processes are delicate, sheet-like structures; but despite this, we found that band 3 protein is relatively abundant in gel samples (not shown) isolated from this part of the ribbon, which contains no myelin.

The pattern of astrocytes in the ribbon optic nerve revealed with Ab3 (Fig. $4 a$ ) resembles that seen with antibodies against GFAP (AbGFAP) in the optic nerves of various vertebrate groups (Dahl and Bignami, 1973; Dixon and Eng, 1981). Ab3 appeared to label all nonmyelin glia in the nerve, and by EM, these cells were densely packed with intermediate-sized filaments (Fig. 6b), except at the growing edge of the ribbon, where IF were considerably sparser in the glial progenitor cells (see Fig. 10,c and d). Among the differentiated astrocytes, we found no morphological indications of the two astroglial classes (types I and II) revealed by surface markers and levels of GFAP expression in mammalian optic nerve (Miller and Raff, 1984; Raff et al., 1983).

Figure $5 a$ shows that the demarcation of band 3-positive astroglia at the optic nerve/tract boundary is a sharp one (large white arrow). The ribbon folds can be traced from the left (small arrows) in this LS, showing that where they coalesce with the tract coincides exactly with the glial interface. This means that the monocular fiber-crossing, occurring at the end of the ribbon, is invested by band 3 astroglia (cf. Fig. $2 a$ ). For comparison with this distribution, Figure $5 c$ shows another LS labeled uniformly across the boundary (arrow) by $\mathrm{Ab} 2$, which recognizes axons (Fig. $5 b$ ), not glia. Bands 2 and 3 are probably equivalent to the $58 \mathrm{kDa}$ complex of axonal and glial proteins found in goldfish optic nerve (Quitschke and Schechter, 1984), and in agreement, $\mathrm{Ab} 2$ and $\mathrm{Ab} 3$ recognized optic axons and astroglia, respectively, in the goldfish.

\section{Band 3 is an intermediate filament protein}

Intermediate-sized glial filaments are extremely abundant in astrocytic cells in the ribbon optic nerve (Fig. $6 a$ ), but very much sparser elsewhere in the CNS, particularly the optic tract (see Fig. 10b). This corresponds with the distribution of band 3, suggesting that this polypeptide is an IF. We obtained evidence 

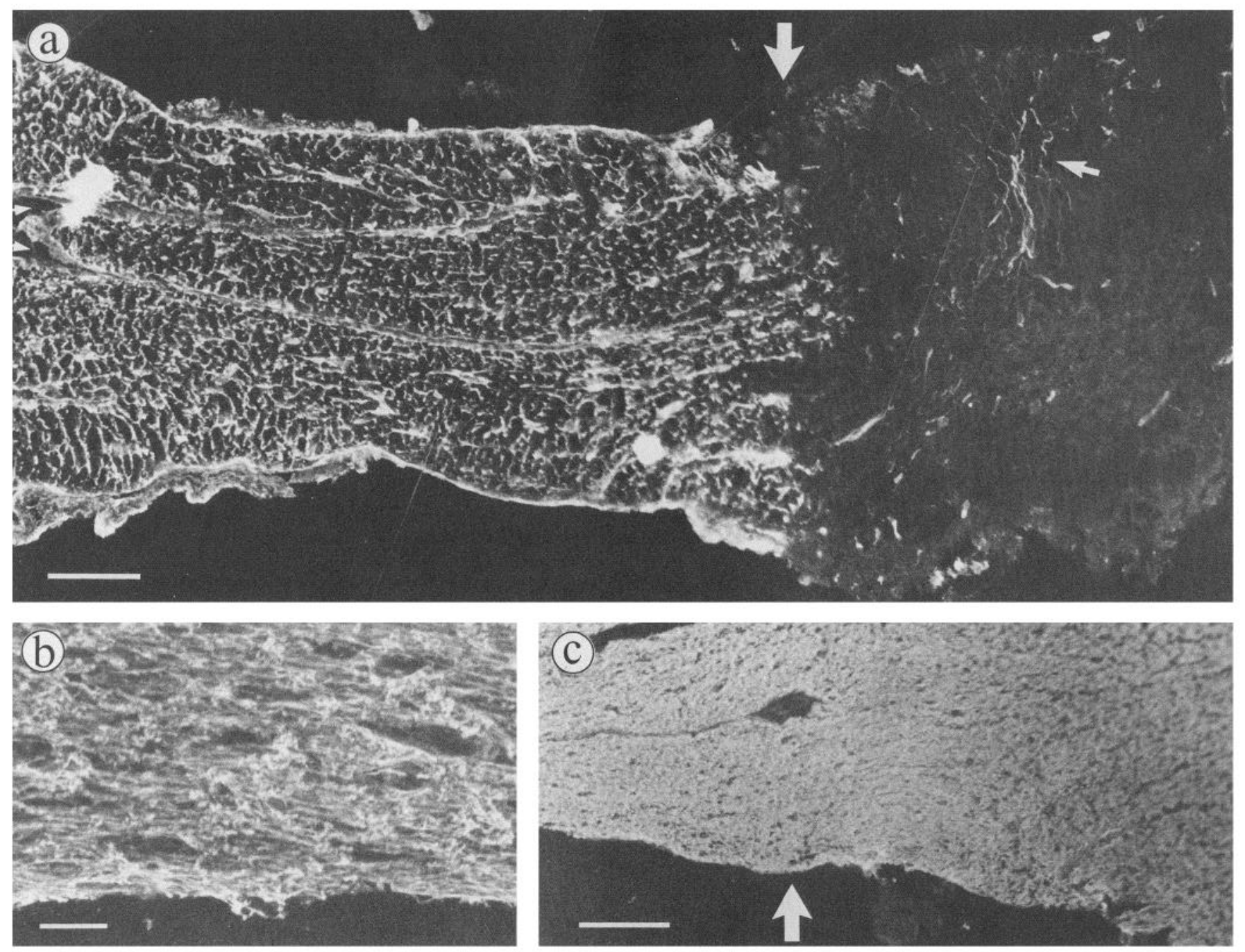

Figure 5. Band 3-positive astroglia in the ribbon optic nerve form a sharp frontier where the nerve joins the optic tract, though the same retinal axons run throughout. $a, \mathrm{Ab} 3$ immunofluorescence in an LS through the nerve/tract boundary. Only a minority of fine glial fibers are labeled in the tract (small arrows, right). The sharp glial boundary (large white arrow) coincides with the end of the ribbon, as seen by tracing the folds from the arrowheads to the left of the micrograph. The stretch of the ribbon shown is roughly the central one-third of the complete optic nerve. Scale bar, $100 \mu \mathrm{m} . b$, Part of an LS of the ribbon optic nerve, enlarged and labeled with Ab2, showing its specificity for retinal axons: dark holes are unlabeled glial processes. Scale bar, $10 \mu \mathrm{m}$. $c$, This LS is for comparison with $A$ (the white arrow indicates the tract boundary). Axonal labeling with $\mathrm{Ab} 2$ is uniform throughout the nerve and tract. Scale bar, $100 \mu \mathrm{m}$.

supporting this indication from immunoblot and immunofluorescence reactions with the IF monoclonal antibody, MAbIF (Pruss et al., 1981), which detects an epitope common to most, if not all, members of this diverse protein family. MAbIF recognized band 3 in immunoblots in its charactersitic distribution between optic nerve, tract and tectal samples (Fig. 6, $d$ and $e$, lanes 1 and 2 ), as well as the variable optic nerve polypeptide, band 7 (Fig. $6 d$, lane 2). The monoclonal also recognized an abundant polypeptide found in tectal samples (Fig. 6e, GF), which was absent in the optic nerve and too sparse for immunoblot detection in the tract (Fig. $6 d$ ). We identify this protein as the fish GFAP, since it migrated close to the $M_{r} 50,000$ GFAP (Chiu et al., 1980) from bovine spinal cord (not shown in Fig. 6 , but see Fig. $7 d$ ), and we confirmed by immunofluorescence (Fig. 7a) that the GFAP-positive astroglia in the tract are relatively sparsely distributed except in a thin surface layer among new optic axons (see Fig. 11c), thus accounting for the negative reactions in blots. Finally, MAbIF reacted with the fish axonal protein, band 2, in all CNS samples (Fig. 6, $d$ and $e$ ).

By immunofluorescence, MAbIF reacted in a pattern that agreed with this spectrum of immunoblot specificities, recognizing axons, optic nerve astrocytic cells, and the sparse astroglia in the optic tract (Fig. 6a), as well as CNS astrocytes generally. We conclude from these results that band 3 is a glial IF subunit, albeit restricted to optic nerve astroglia. We attempted a critical confirmation by trying to reconstitute filaments from protein eluted from gels, but failed to find permissive conditions for assembly.

\section{Is band 3 related to $G F A P$ or vimentin?}

What is the relation of band 3 to GFAP, the principal glial filament in other optic nerves? On the ground of characteristic molecular weight ranges $(56,000$ vs 50,000 for mammalian GFAP; Eng and DeArmond, 1982), there should be none, and in agreement we found that a rabbit anti-human GFAP antiserum (Pruss, 1979) reacted with none of the major optic nerve polypeptides in immunoblots, let alone with band 3 (Fig. $7 d$, lane 3 ). This was not a species cross-reactivity problem, since the AbGFAP did recognize the CNS $M_{r} 50,000$ band, identified immunologically as an IF in Figure $6 e$, lane 1 , which must 

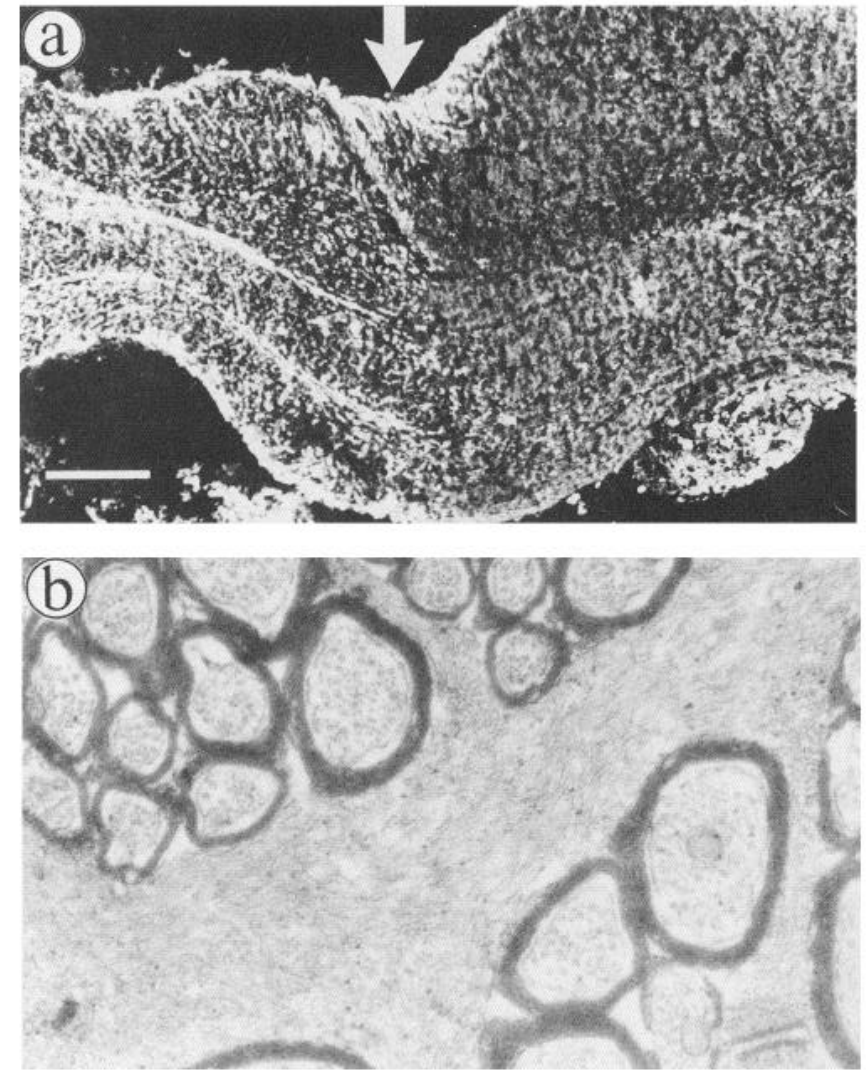

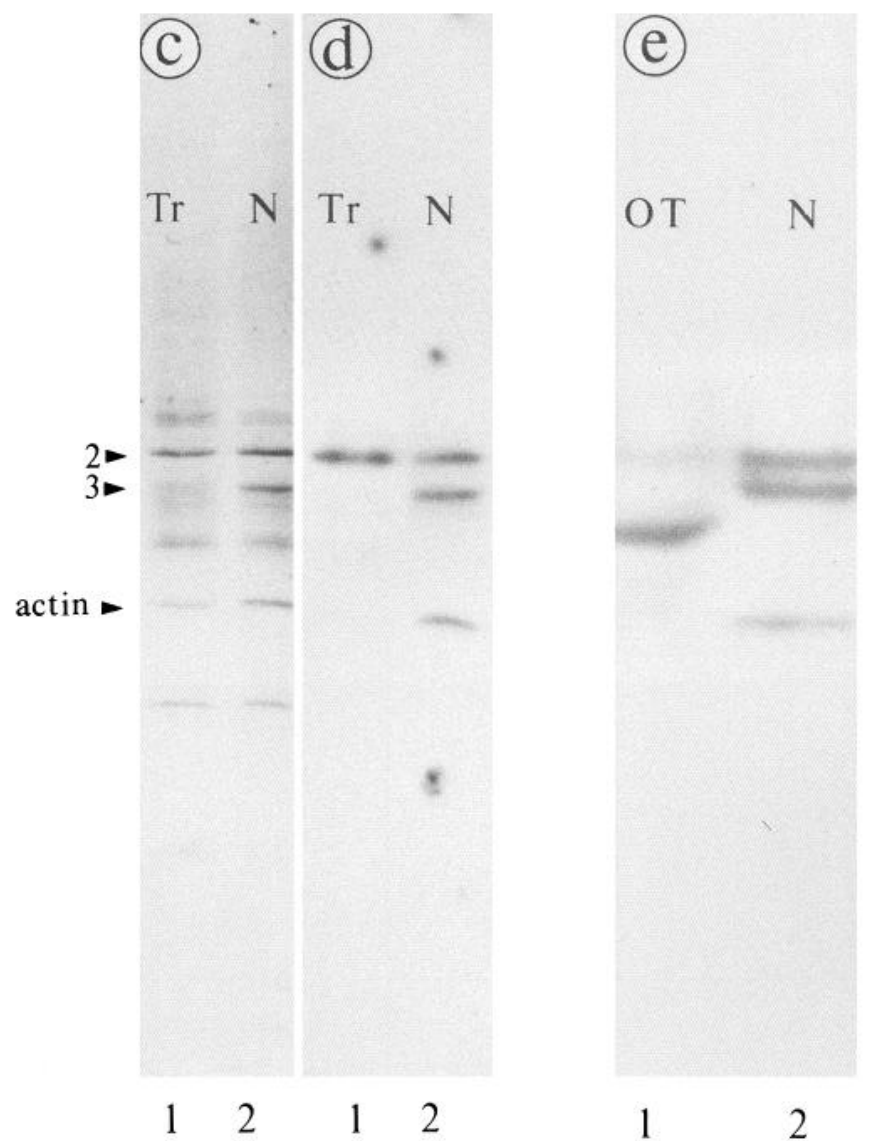

Figure 6. The IF-specific monoclonal, MAbIF (Pruss et al., 1981) recognizes band 3 and other glial and axonal IF in the fish optic nerve and CNS. $a$, Immunofluorescence with MAbIF in an LS through the boundary (arrow) between the optic nerve (left) and the optic tract (right). The pattern is as if parts $a$ and $c$ in Fig. 5 were superimposed, and agrees with the immunoblot analysis in $c-e$. Scale bar, $100 \mu \mathrm{m}$. $b$, The array of glial IF in an astrocytic process among myelinated fibers in the ribbon optic nerve. $\times 30,000 . c$, SDS-PAGE of optic tract $(T r$, lane 1$)$ and optic nerve $(N$, lane 2) showing the locations of bands for comparison with $d$ and $e$. $d$, Immunoblot of gel lanes similar to to those in $c$, labeled with MAbIF. The IF-specific monoclonal reacted in the nerve $(N$, lane 2$)$ with axonal band 2 and glial bands 3 and 7 (the latter slightly below actin and not visible in $c$ ), and only detected band 2 in the tract $(T r$, lane 1$)$. $e$, Reactivity of MAbIF in an immunoblot of optic tectum (OT, lane 1$)$ compared with that of the optic nerve ( $N$, lane 2) samples. The monoclonal recognized an abundant tectal IF (GF) at $50 \mathrm{kDa}$ in lane 1 , as well as band 2 , which was relatively sparse. Lane 2 shows optic nerve bands 2,3 , and 7 for comparison.

therefore be the fish GFAP (Fig. 7d, compare lanes 1 and 4). These results were supported by immunofluorescence with AbGFAP, which showed a complementary distribution to that with Ab3. Thus AbGFAP recognized sparse glial processes in the tract (Fig. 7a), insufficient for detection by immunoblotting (Fig. $7 d$, lane 2), as well as extensive astroglial processes and endfeet throughout the brain (Fig. $8 a$ ) and spinal cord. However, there was no reaction in the ribbon (Fig. $7 b$ ), confirming an early report that fish optic nerves are GFAP-negative (Dahl and Bignami, 1973).

Is band 3 related to vimentin? This IF, originally supposed to be mesenchymal (Franke et al., 1978), is the only other major cytoskeletal protein expressed by mammalian astroglia, both in situ (Dahl et al., 1981; Shaw et al., 1981) and in vitro (Yen and Fields, 1981), and it seems to characterize white matter astrocytes of the fibrous type (Peters et al., 1976; Raff et al., 1984; Shaw et al., 1981). Perhaps, like Mueller cells in mammalian retina (Shaw and Weber, 1983), fish optic nerve astrocytes have settled for vimentin alone.

Three lines of evidence strongly suggest that band 3 is fish vimentin, although it is uniquely restricted in the CNS to glia in the ribbon optic nerve, and is by no means identical in other respects with vimentin in mammals. First, band 3 is an IF subunit in the right molecular weight range for vimentin (5458,000; Franke et al., 1979; Lazarides, 1982), and, more im- portant, the fish had no other candidate for vimentin identity. For example, the only other nearby IF bands detected by MAbIF in the CNS (Fig. 6, $d$ and $e$ ) were the $M_{r}$ 50,000 AbGFAPpositive band (Fig. $7 d$ ), localized in brain astrocytes (the fish GFAP; Fig. $8 a$ ), and band 2 at $M_{r} 61,000$, located only in axons.

The second line of evidence, upon which we place the most weight, is that the tissue distribution of band 3 was similar, though not identical, to that of vimentin in mammals. Ab3 labelled glia and glial progenitor cells, although in the ribbon nerve only, and also CNS capillaries and meninges, in patterns like those seen with anti-vimentin antibodies in the mammalian CNS (Shaw et al., 1981; Yen and Fields, 1981). Outside the $\mathrm{CNS}, \mathrm{Ab} 3$ recognized fibroblasts but not striated muscle fibers. It labeled vascular endothelium (cf. Schmid et al., 1982), kidney tubule and ocular lens cells (cf. Lazarides, 1982), as well as some gut epithelia, and blotted at band 3 molecular weight with gel samples of these tissues (Fig. 8, $c$ and $d$ ). An exception to the mammalian vimentin pattern (Shaw and Weber, 1983) was that the fish retinal Mueller cells lacked band 3: however, these are anomalous, expressing GFAP (Bignami, 1984), so this is no serious counterindication for the proposed vimentin-like identity of band 3 .

Finally, Ab3 revealed a characteristic vimentin-like pattern of acidic breakdown products (cf. Lawson, 1983) in blots of 2-D isoelectric focusing gels. Attempts to widen this comparison 

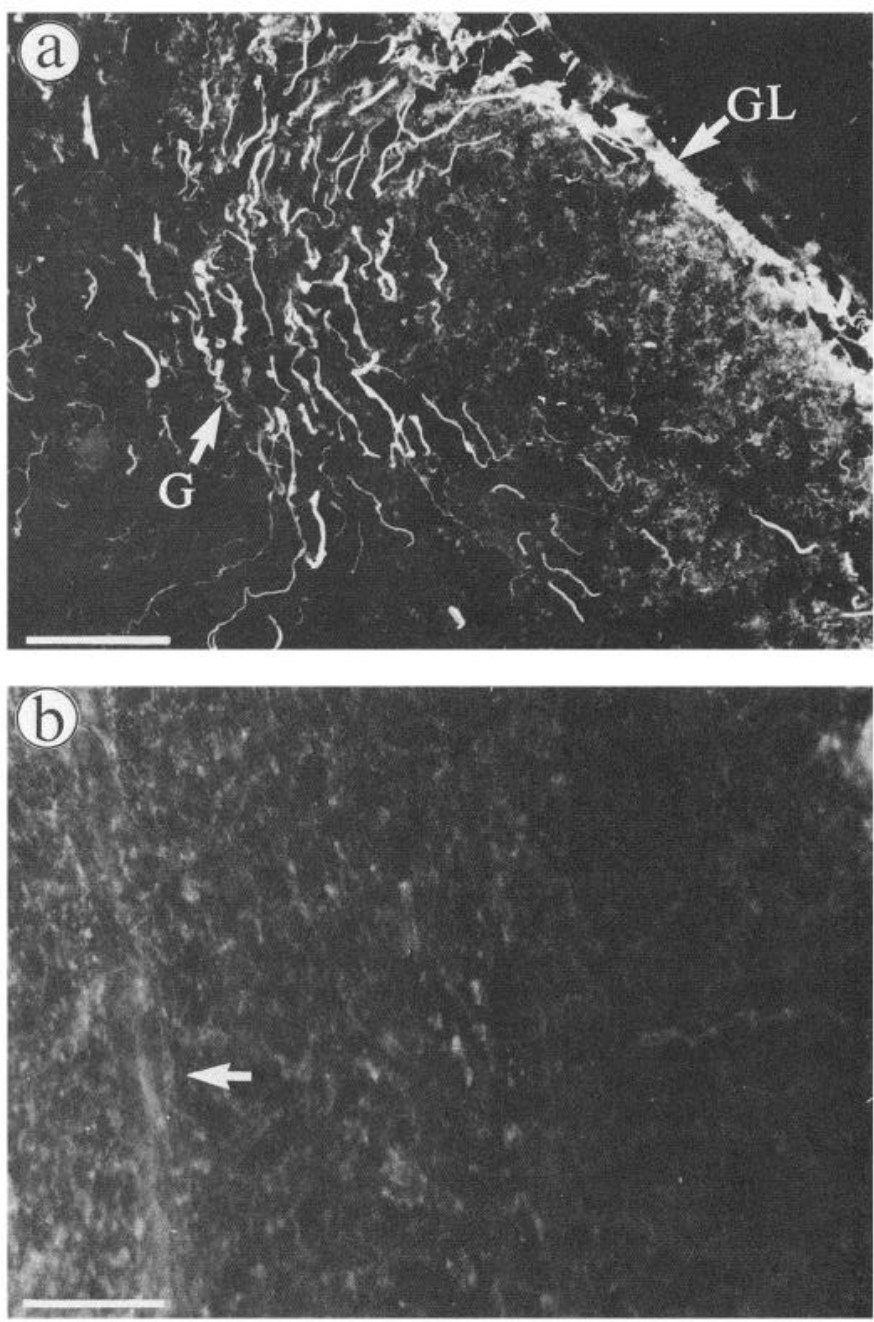

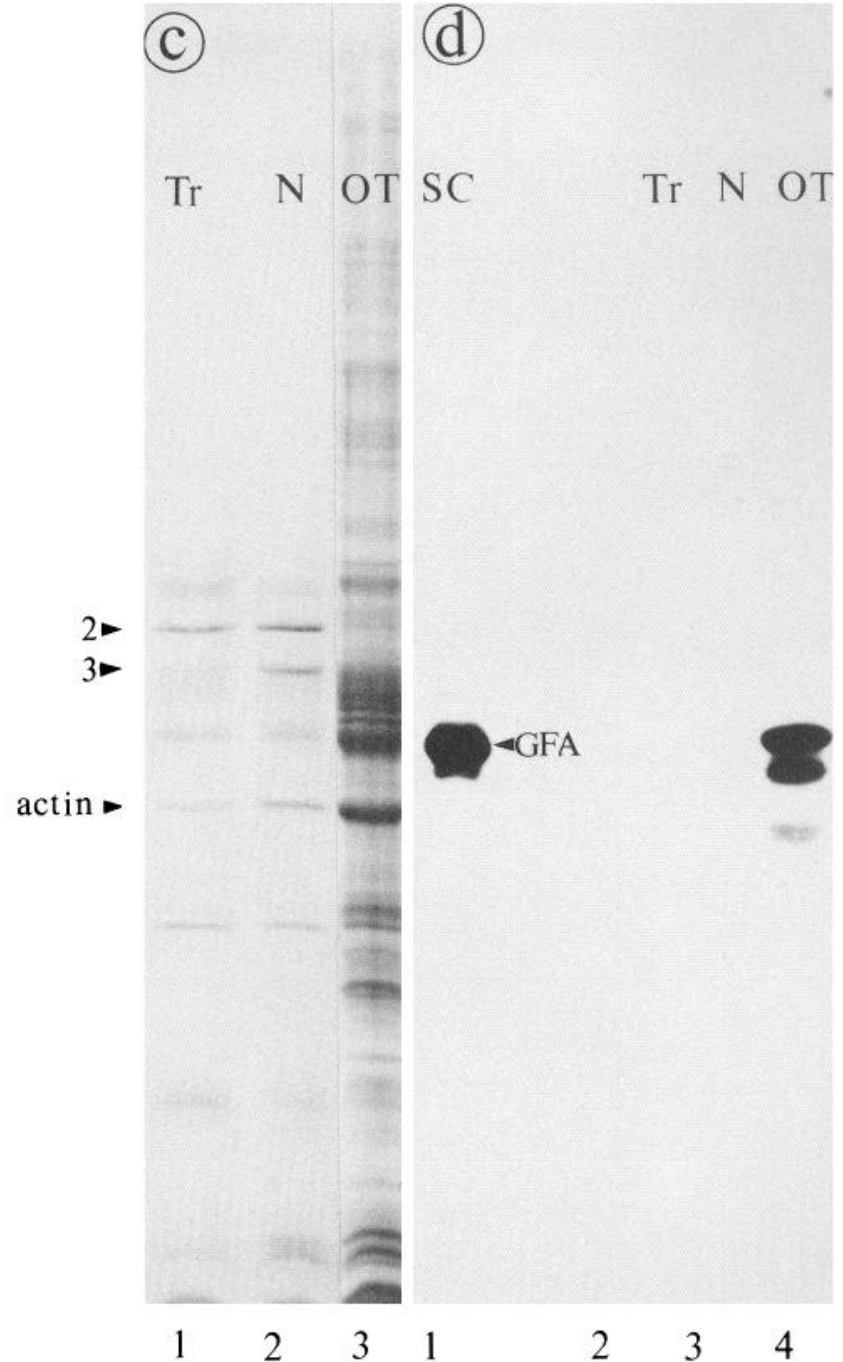

Figure 7. Fish optic tract astrocytes are GFAP-positive, but the optic nerve glial network lacks this ubiquitous glial IF. $a$, A cluster of GFAPpositive astroglial processes radiating from the surface glia limitans $(G L)$ in an LS of the fish optic tract. Scale bar, $25 \mu \mathrm{m}$. $b$, Reacted alongside the section in $a$, this LS of the ribbon nerve is GFAP-negative (cf. Dahl and Bignami, 1973). The arrow indicates a ribbon fold: Scale bar, $25 \mu \mathrm{m}$. $c$, SDS-PAGE of optic tract (Tr, lane 1$)$, optic nerve $(N$, lane 2$)$, and optic tectum $(O T$, lane 3$)$ samples for comparison with the AbGFAP immunoblots in $d$. $d$, Immunoblot showing that the AbGFAP (Pruss, 1979) reacts at GFAP molecular weight with fish as well as mammalian material. Lane 1, The blotted gel lane was a bovine spinal cord (SC) intermediate filament preparation showing the $50 \mathrm{kDa}$ mammalian GFAP $(G F A)$. Lane 2, AbGFAP detects no GFAP in the optic tract $(T r)$ where the astroglial network is very sparse. Lane 3, The optic nerve $(N)$ is GFAPnegative. Lane 4, Tectal sample showing AbGFAP binding at about $50 \mathrm{kDa}$, confirming that the fish brain glial IF (Fig. 6) is GFAP-like (cf. lane 1).

failed because $\mathrm{Ab} 3$ did not recognize mammalian cytoskeletons, and various anti-vimentin reagents were negative for fish material. These included two polyclonals (Hynes and Destree, 1978; Jacobs et al., 1982) and two commercially available monoclonals (Ramaekers et al., 1982; Virtanen et al., 1981). Also, peptide-mapping with papain did not detect similarities between band 3 and vimentin (data not shown). However, it is well known that vimentins are not conserved immunologically between vertebrate groups (Lazarides, 1982), and we therefore conclude from our evidence that band 3 is a fish variant of the vimentins found in higher vertebrates.

\section{Glial structures and axonal extension}

Among other changes, growing optic fibers assort into a new tectotopic pattern at the nerve/tract boundary. How could this behavior relate to the sharp segregation of vimentin and GFAPlike IF in the astroglia on either side of this interface? One possibility is that special tensile or motile properties of the glia, determined by their cytoskeletons, mechanically package the growing fibers appropriately. Alternatively, the glia may express characteristic surface ligands that are more directly influential for axonal growth, correlated with their different patterns of cytoskeletal proteins (cf. Noble et al., 1984; Raff et al., 1983). With such possibilities in mind, we examined growing axons in the optic nerve and tract for signs of interaction with the glia that could explain the formation of the monocular fiber-crossing near the interface between these tissues.

New, unmyelinated retinal axons are arranged in a compact bundle at the growing edge of the ribbon, but spread in a thin layer over the surface of the optic tract, diverging towards the tectal brachia (cf. Fig. 12). They are very small and prodigiously numerous, with up to 50,000 in each nerve in fast-growing fish (R. Karam, personal communication), compared with, say, 250,000 myelinated axons in a six-month-old nerve. Growth cones extend, at the extreme edge of the ribbon, over the surface of the unmyelinated fibers (Figs. 9, 10a, and 11a). 

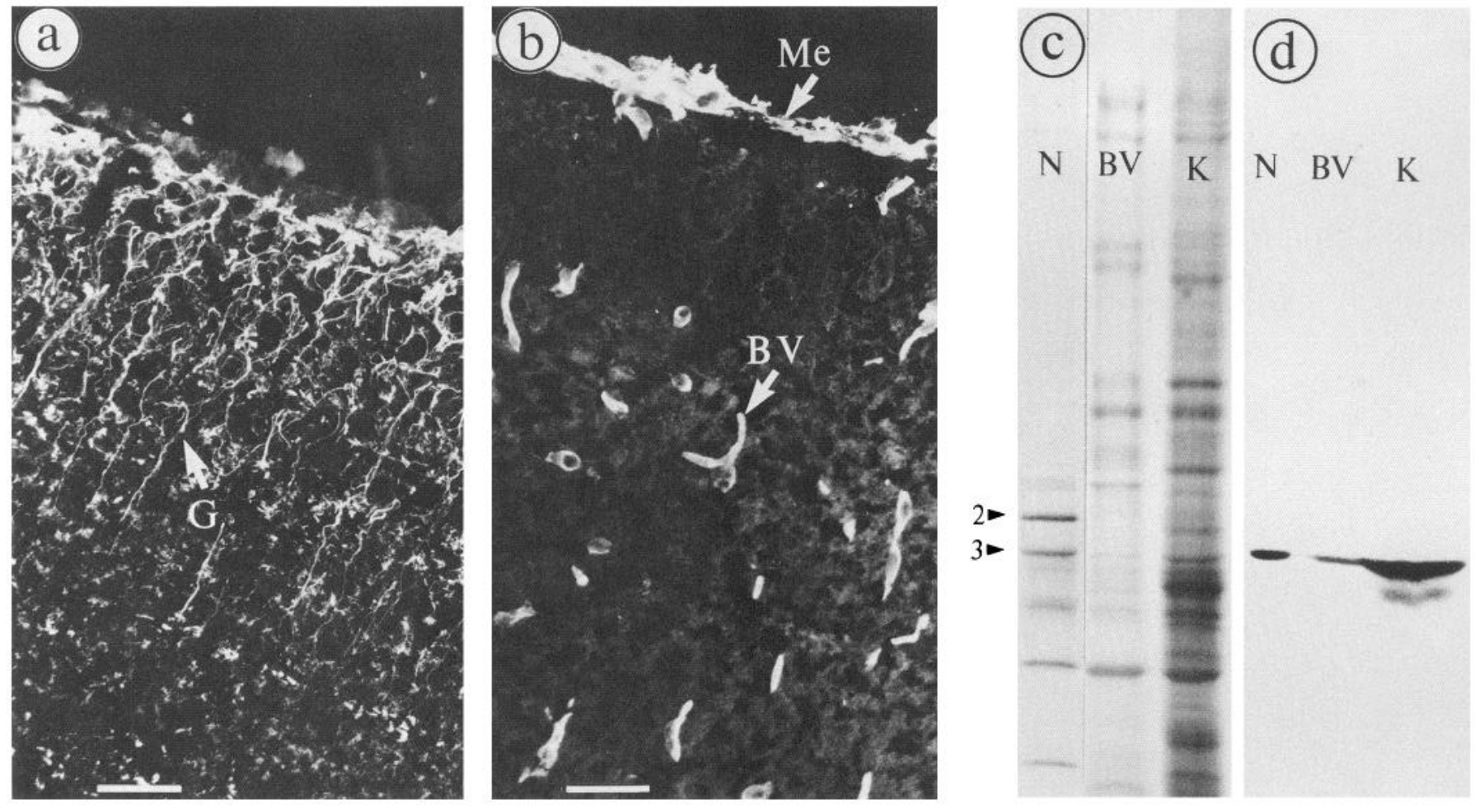

$\begin{array}{llllll}1 & 2 & 3 & 1 & 2 & 3\end{array}$

Figure 8. The tissue distribution of band 3 in fish is vimentin-like. $a$ and $b$, These immunofluorescence micrographs compare labeling of tectal sections with AbGFAP and Ab3, respectively. $a$, AbGFAP reveals the astroglial network $(G)$ connected to the surface glia limitans; in $b$, Ab3 labels capillaries $(B V)$ and meningeal membrane $(M e)$ only. Scale bars, $25 \mu \mathrm{m}$. $c$, SDS-PAGE of optic nerve (lane $1, N)$, a capillary bed preparation from the fish ocular choroid rete (lane $2, B V$ ), and a fish kidney sample (lane 3, $K$ ), for comparison with the immunoblot in $d$. $d$, Immunoblot using $\mathrm{Ab} 3$ against optic nerve, blood vessel, and kidney samples (lanes $1-3 ; N, B V$ and $K$, respectively, as in $c$ ), showing that the antiserum reacts at band 3 molecular weight in neural and non-neural samples alike.

By serial sectioning, showing the continuity of these structures with axons, we compiled clear criteria for recognizing growth cone profiles in sampled sections. Figure 9 shows different levels along some growth cones from a run of 400 thin serial cross sections over a distance along the nerve we estimated as about $45 \mu \mathrm{m}$. For practical purposes, these growth cones are very similar to those recently described by Easter et al. (1984). Near the leading edge (growth cone 1 in Fig. $9 a$ ), they have a leading lamella and completely lack filopodia. At the surface of the nerve, the lamellae are simple and flat, as shown. If, as is sometimes seen, the growth cones are located deeper among the other axons, the organization is more complex - for example, triradiate or cruciform. Behind the leading lamella, the growth cones are usually paddle-like in shape, with a central thick spine and lamellar extensions at the side (Fig. $9 b$ ). The spine contains accumulated microtrabecular membrane material, and numerous microtubules (Fig. 9, $b$ and $c$ ), perhaps up to 30 . In counting growth cones (see below), we included only large profiles $(>1$ $\mu \mathrm{m})$ of leading lamellae containing microfilament fuzz, or of growth cone bodies containing membrane trabeculae and microtubules. These were quite distinct from glial processes, which were recognized by their IF (Fig. 10,b and $c$ ).

In the direction of the eye, the growth cones taper back into long, axonal structures, which we regard as distinct from growth cones and call "wrists" ( $w$ in Figs. 9 and 10). These are initially 1-2 $\mu \mathrm{m}$ in diameter, with simple oval-to-round, profiles lacking neurofilaments but packed with microtubules and associated membrane trabeculae. The wrists are packed at the edge of the ribbon, under the growth cones, typically within a cross-sectional area like that bounded by the stippled line in Figure $11 a$. They taper back gradually into the fine $(0.15 \mu \mathrm{m})$, unmyelinated axons that are stratified further from the edge of the ribbon, to the right of the stipple in Figure $11 a$. The size contrast between the wrists and the fine fibers trailing behind them, which had a few neurofilaments and perhaps one to two microtubules, is shown in Figure 10, $c$ and $d$.

The layer of wrists at the edge of the ribbon thus presents a specialized substrate for growth cone extension, seemingly shielding the tens of thousands of finer, unmyelinated fibers underneath from growth cone contact. The number of wrists is of some interest. In a typical EM cross section, for example, we counted about $30 \times$ as many wrists as growth cones (456 vs 14 : a conservative count with a diameter range of $0.2-0.5 \mu \mathrm{m}$ ). From serial sections we estimate that growth cones are at least $15 \mu \mathrm{m}$ long; thus wrists themselves are very long, trailing at least $0.5 \mathrm{~mm}(15 \times 456 / 14 \mu \mathrm{m})$ behind the growth cones proper.

Although spread out extensively in a superficial layer, axons and wrists in the tract appeared broadly similar to those in the nerve. However, the astroglia differed radically, as expected from the immunofluorescence patterns (Figs. $4 e$ and $7 a$ ), both in cytology (compare Figs. $6 b$ and $9 b$ ) and in configuration (Fig. $11, a$ and $c$ ). IF were extremely sparse in the tract astroglia (Fig. $10 b$; see arrowheads, top right) compared with the dense arrays seen in the nerve (Fig. 6b). Astroglial processes in the tract, especially just below the glia limitans, were much more prolific (Figs. $10 b$ and $11 c$ ) than was revealed by AbGFAP fluorescence (Fig. 7a), and were mostly protoplasmic (Peters et al., 1976), lacking IF. This agreed with the distribution of glial IF assayed by immunoblots, found to be absent or sparse in the tract compared with optic nerve and tectum (Figs. 6, $c-e$ and $7 d$ ).

The glia limitans of the optic nerve is parted in a continuous suture line along the extreme growing edge of the ribbon (see 

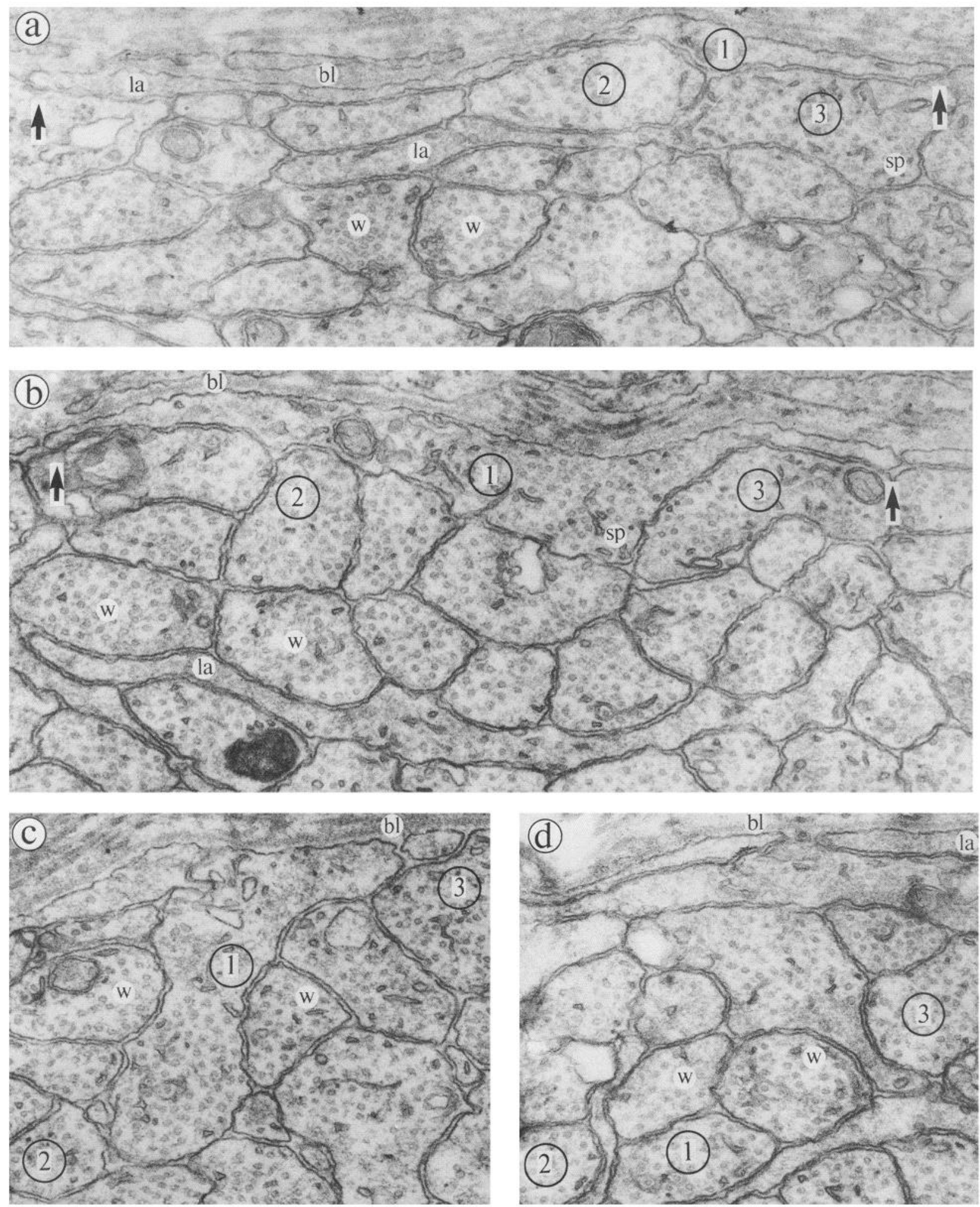

Figure 9. Cross sections of extending axonal processes in the ribbon optic nerve from a run of nearly 400 serial sections, showing the appearance of structures associated with growth cones at various levels. Three growth cones $(1-3)$ are traced through the series represented by $a-d$, showing their connection with axons. The series was photographed every 10 or fewer sections, and the area sampled is close to the edge of the ribbon, in a position similar to that in $10 c$ in Fig. $11 a$, lacking glial processes. The structures labeled (not the same ones in each section) are some growth cone lamellae (la) and spines $(s p)$, some wrists $(w)$, as well as the superficial basal lamina $(b l) . \times 63,000 . a$, The extent of the leading lamella of growth cone 1 is marked with arrows. Growth cone 3 has a lamellar process $(l a)$, and two nearby axonal wrists are marked $w$. $b$, At this level, about $10 \mu \mathrm{m}$ towards the eye, growth cone 1 has a central spine $(s p)$, which is flanked by lateral lamellae $(l a)$, while 2 and 3 have attenuated into wrists. $c$, A further $12 \mu \mathrm{m}$ towards the eye, the spine of growth cone 1 merges with a more deeply stratified wrist-like profile. $d$, Roughly $18 \mu \mathrm{m}$ further back, all three structures now have simple wrist profiles, deeply stratified among neighboring fibers. 

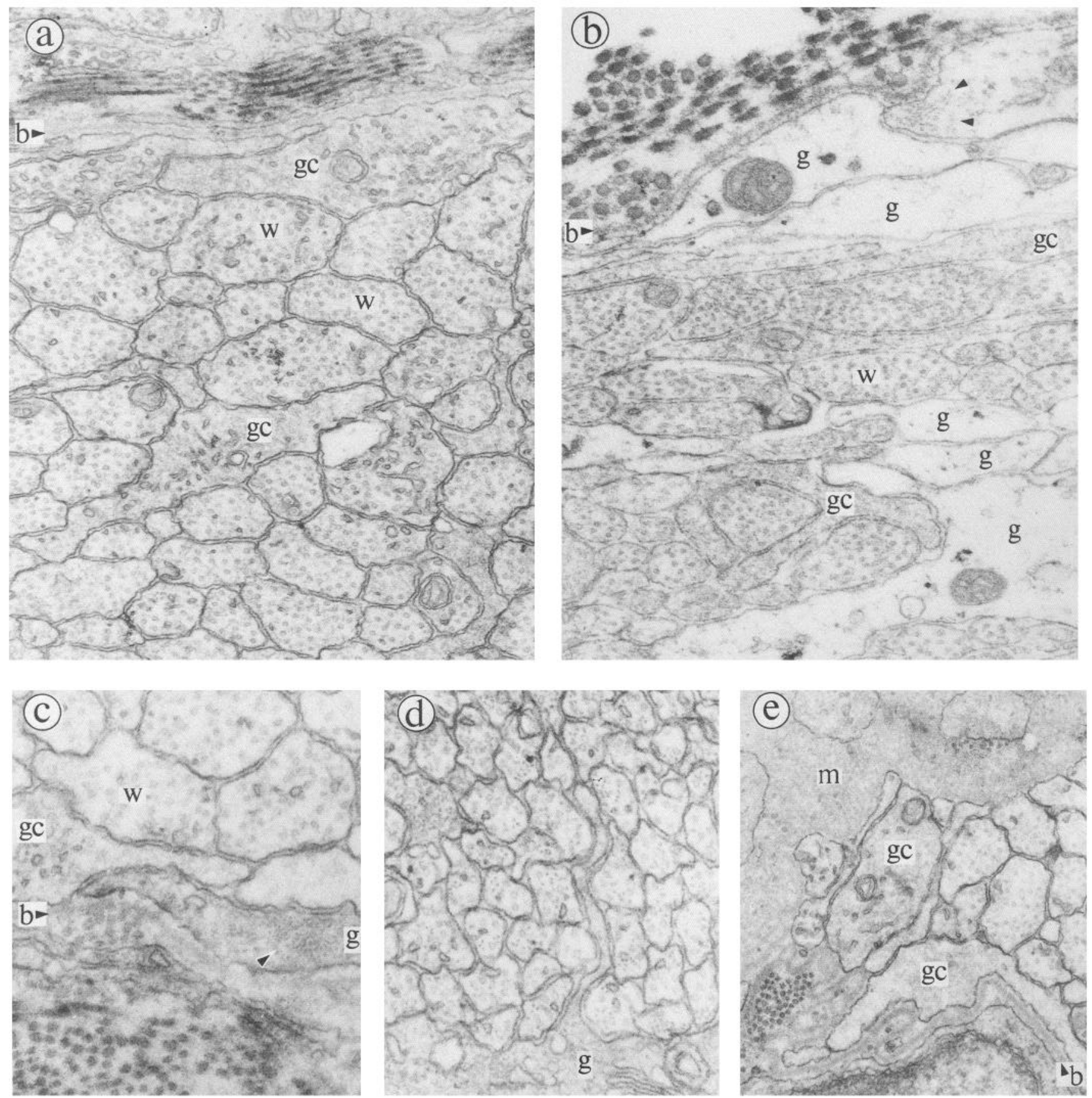

Figure 10. Electron microscopy of growing fibers in cross sections of the ribbon optic nerve and the optic tract, illustrating the structure of growth cones and their relations with glia and basal lamina. The locations of some of the micrographs are indicated (10c, etc.) in Fig. 11. $a$ and $b$, Compare the disposition of growth cones $(g c)$ in the optic nerve and tract, respectively. In the nerve $(a)$, growth cones are mainly located in contact with the basal lamina $(b)$, overlying a packed layer of axon wrists $(w)$. In the tract $(b)$, glial processes $(g)$ form a glia limitans separating the growth cones from the basal lamina. The tract astroglia are protoplasmic, with very sparse glial IF (arrowheads, top right). The tract growth cones are somewhat obliquely sectioned because of their decussation towards the tectal brachia. $\times 44,000$ in both parts. $c$ and $d$, These micrographs came from the areas marked $10 c$ and $10 d$ in Fig. $11 a$ and compare growth cones and wrists $(g c, w$ in part $c)$ with the fine unmyelinated fibers (part $d)$ stratified away from the edge of the ribbon. Part $c$ shows how growth cones can easily be distinguished from the processes of neighboring glial progenitor cells $(g)$, which are recognized by their glial IF (arrowhead). $\times 56,000$ in both parts. $e$, Reactive basal lamina is folded up into an elaborate handrail at the growing edge of the ribbon, where the glia limitans opens in a narrow suture line running between the eye and the optic tract ( $m$, matrix). The position of this micrograph is indicated $(10 e)$ in Fig. $11 a . \times 27,000$.

arrows in Fig. $11 a$ ) so that growth cones gain access (Figs. 9 and $10 a$; cf. Easter et al., 1984; Jackowski and Lieberman, 1979) to the basal lamina, forming a continuous file between the eye and optic tract on this matrix material. This contact with optic nerve basal lamina is completely denied to growth cones in the optic tract (Figs. $10 b$ and $11, b$ and $c$ ).

At the edge of the ribbon, the file of growth cones and wrists is flanked on both sides, as if shepherded, by a narrow germinal 
Figure 11. These drawings were traced from EM montages at original magnification of $\times 10,000$. They are cross sections through the file of growing axons at three different levels in the same visual pathway, showing the changing relation of the growth cones (open shapes) to matrix material $(m)$ and the glia (black shapes). The tracings $(a-c)$ come from inside the areas indicated by boxes in the diagrams of Fig. 12. Scale bar, $10 \mu \mathrm{m}$. Abbreviations: $g$, glia; $g l$, glia limitans; $g f$, glial feet; $p r$, glial progenitor cells; $m$, basement membrane; $p$, pia. $a$, Section through the growing edge of the ribbon (Fig. 12, left). $p$ is the surrounding pial membrane, growth cones are the open shapes to the left, contacting the basal lamina matrix $(m)$. The glial progenitor cells $(p r)$ are located at the surface, and they differentiate in sequence from left to right, pulling their nuclei away from the glia limitans $(g l)$. The arrows show the margins of the glial suture, and myelination begins at the dashed line (right). Labels 10c$e$ indicate the locations of those parts of Fig. 10. Stippled line separates wrists to the left from unmyelinated axons to the right. $b$, Growth cone and glial dispositions at the optic nerve/tract boundary (see Fig. 12, middle). Abbreviations and conventions as above. The growth cones are sealed from the basement membrane $(m)$ by a continuous glia limitans. Dashed line, Onset of myelination. $c$, Part of the growing fiber layer in the optic tract (Fig. 12, right) showing how growth cones are dispersed in contact with the glia limitans $(g l)$, glial processes $(g)$ and vascular endfeet $(g f)$. Note how different the glial outlines (black shapes, cf. Fig. $10 b)$ are in this section. Dashed line indicates onset of myelination.
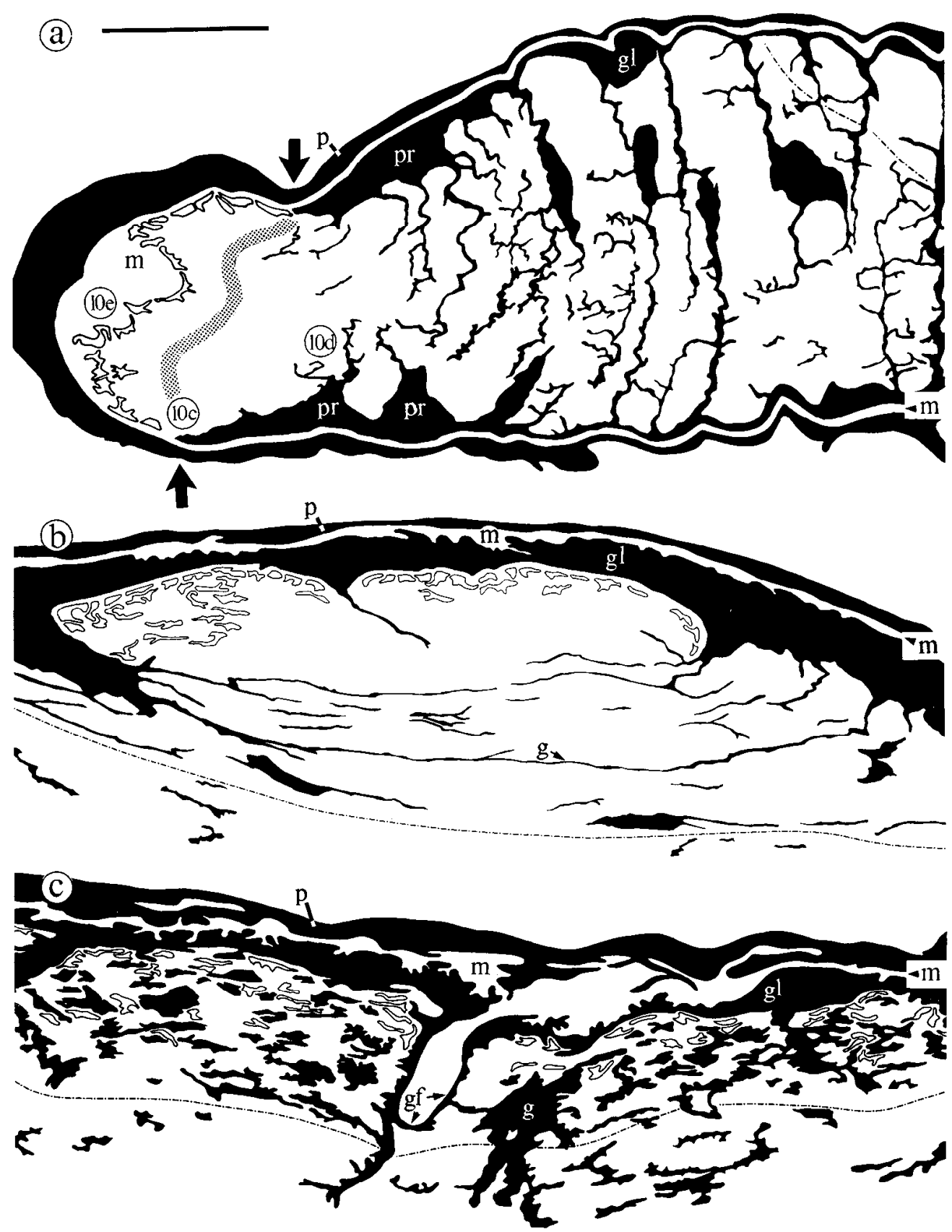

strip of glial precursor cells, which are band 3-positive and contain IF (Figs. $4 e$ and $10 \mathrm{c}$ ). The superficial location of these cells, which we verified as mitotic with $3 \mathrm{H}-\mathrm{TdR}$ (unpublished observations), is shown in Figure $11 a$ (pr). CNS glial surfaces generally present the substrate for axonal growth during development (cf. Nordlander and Singer, 1982; Singer et al., 1979), but here growth cones and glial surfaces appear to be incompatible. Thus, glial processes are excluded from the file of growth cones and wrists (Fig. 11a), and the growth cones appear to capture basal lamina from them, tending to modify this material so that it folds into a thick reactive strand (Figs. 10e and 11a), like a handrail.

In contrast with the nerve, the astroglia in the tract (protoplasmic in character, with vascular endfeet) form an elaborated, multilayered glia limitans (Fig. 10b, top), completely sealing the tract (Fig. 11,b and $c$ ) so that axons never have access to the basement membrane, itself quite different from that in the nerve (cf. Fig. 10, $a$ and $b$, especially the collagen). Also contrasting with the nerve, where glia are excluded from among the growth cones, astroglial processes in the tract are much more prolific among the growing fibers (Fig. $11 \mathcal{c}$, above dashed line) than elsewhere. Again contrasting with the nerve, the astrocytes appear hospitable to growth cones, which contact them indiscriminately (Figs. $10 b$ and $11, b$ and $c$ ), in addition to wrists.

The above comparisons are summarized in Figure 11, which shows outlines traced from EM montages of cross sections at different levels in the same preparation, in the ribbon (Fig. 11a), at the tract boundary (Fig. $11 b$ ), and in the tract itself (Fig. 11c). The montages were compiled within the boxed areas shown for oricntation in the diagrams of Figure 12. The drawings in Figure 11 , where growth cones are indicated by open shapes, bring us to a final spectacular contrast between the optic nerve and tract.

We counted growth cone profiles, identified in montages at $\times 10,000$ by the criteria discussed in connection with Figure 9 , from the three sections shown. The counts included substantial profiles of leading lamellae and growth cones proper, like those 
in Figure 9, $a-c$, but ignored axon wrists. The counts are given above Figure 12, showing that about $10 \times$ as many growth cones are intercepted in the tract as in the nerve, and that this increase begins at the tract boundary (Fig. 12, second diagram; cf. Fig. $11 b)$ as soon as the glia limitans seals over the growing fibers. We consistently observed similar distibutions of growth cones in other nerve and tract preparations.

This phenomenon bears comparison with a departure lounge. On the escalator leading to it, a cross section intercepts only a couple of travelers (Figs. $11 a$ and 12, left). In the lounge itself, many more are seen, spreading out and allying themselves with fellow passengers (Figs. $11 c$ and 12, right) before, in this case, leaving for the tectal brachia. In reality, of course, various factors could account for the accumulation of growth cones in the tract, among them increased growth cone complexity and exploratory axonal branching.

\section{Discussion}

The fish optic nerve contains a unique astroglial network, retaining certain embryonic characteristics - in particular, vimentin-like glial IF. The progenitor cells that make this network, during growth, also tightly shepherd new optic nerve fibers, favoring swift axonal extension. In contrast, where the growing fibers escape from this restraint at a sharp interface with GFAPpositive CNS astroglia in the optic tract, their progress is impaired, favoring exploration. Properties of this glial boundary may explain development of the peculiar form of optic chiasm in fish, as well as formation of the monocular retinotectal fibercrossing.

\section{Band 3 and vimentin}

Band 3 is an abundant cytoskeletal protein made by nonmyelin glia in the fish optic nerve, with about the same molecular weight as vimentin in higher vertebrates. We identified it as an intermediate filament subunit, using the IF-specific monoclonal antibody (Pruss et al., 1981), which reacts reliably with this class of proteins in various widely separated vertebrate groups (Nelson and Traub, 1982). The monoclonal recognized various axonal and glial polypeptides in the fish (Fig. 6), but none, apart from band 3, that could qualify for vimentin identity. Moreover, band 3 is expressed in a tissue pattern outside the optic nerve (Fig. 8 and text), resembling the in vivo distribution of vimentin in mammals.

These were the principal grounds for our conclusion that band 3 is the fish equivalent of vimentin in higher vertebrates, but the two proteins are not identical. Various vimentin antibodies were negative with fish material, as was Ab3 with mammalian and avian cytoskeletons, and peptide maps of band 3 and vimentin revealed no significant homologies. However, these stringent tests by no means exclude relatedncss, and vimentins are known to be ill-conserved between vertebrate groups. The mammalian and avian variants are immunologically distinct (Lazarides, 1982), and we have noted (unpublished observations) optic nerve glial filament diversity even between different fish families. For example, glial IF protein in the $58 \mathrm{kDa}$ complex (Quitsche and Schechter, 1984) from goldfish (Cypriniformes) optic nerve is immunologically related to band 3 in cichlids (Perciformes), but of somewhat higher molecular weight.

The functions of vimentin-like proteins are not known. Vimentin is retained as a cytoskeletal clement by a haphazard pattern of adult tissues, e.g., CNS astroglia and vascular endothelium (Lazarides, 1982). However, it is primarily characteristic of mitotic and disseminating cells of all potential types, as has been seen in culture and embryonic tissues (Dahl et al., 1981; Lane et al., 1983; Franke et al., 1979; Tapscott et al., 1981). The expression, cytoskeletal organization and phosphorylation of vimentin-like proteins is regulated during cellular motile responses and mitosis (Ben Ze'ev, 1984; Dulbecco et al.,

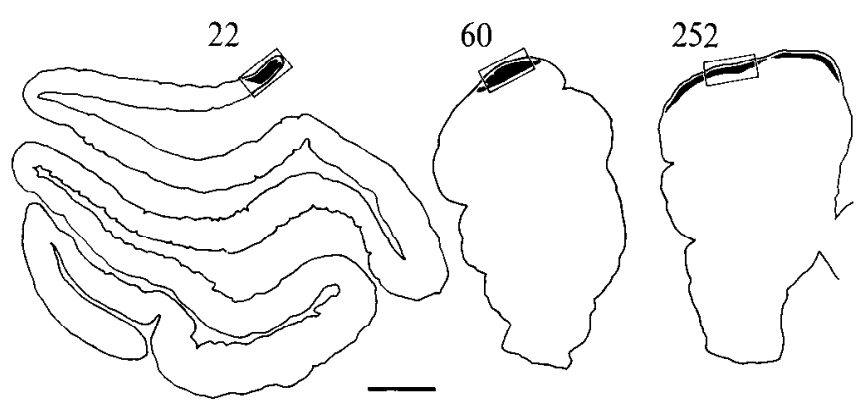

Figure 12. Ten times as many growth cone profiles (252 vs 22) were found in the optic tract as in the ribbon nerve in sections at different levels in the samc visual pathway. Outlines of the three visual pathway sections from which the tracings of Fig. 11 (inside the boxes) were taken. Black indicates the growing unmyelinated fibers, perhaps 30,000 in number. The numbers above each drawing are counts of all growth cones and substantial leading lamella profiles in the entire sections; only a selection are drawn in Fig. 11. Scale bar, $100 \mu \mathrm{m}$.

1983; Evans and Fink, 1982; Lane et al., 1982), suggesting that they may have some direct functional association with these cell activities.

\section{Band 3 and morphogenesis of the ribbon optic nerve}

Contrasting with the distribution of vimentin in mammalian glia, band 3 is confined to astrocytic cells of the ribbon optic nerve (Fig. 5), and not expressed in brain (Fig. $8 b$ ) and spinal cord astroglia. To judge from growth cone counts (Fig. 12), new axons extend swiftly through this specialized glial environment. Are there any special features of the optic nerve astrocytes that could underlie formation of the peculiar ribbon-like structure and facilitate axonal growth?

Band 3 has a dual distribution in the optic nerve: as mechanical armor in established astrocytes, on one hand, and in glial precursor cells, on the other. The optic nerve glial precursor cells are located along the extreme growing edge of the ribbon, the youngest of them (pr in Fig. 11a, as confirmed in unpublished $3 \mathrm{H}-\mathrm{TdR}$ studies) bordering the file of new growth cones. They have much sparser IFs than the hypertrophied filament arrays in the mature astrocytes (compare Figs. $6 b$ and $10 c-d$ ). During differentiation, as shown in sequence from left to right in Fig. $11 a$, these cells invasively ramify processes through the array of new optic axons, to establish endfeet on both surfaces of the ribbon. The resultant cell shapes, with the somas now in the interior of the ribbon (Fig. $11 a$, right, and Fig. 4, $c$ and $d$ ), resemble embryonic radial glia (tanycytes), except that they bridge two pial surfaces rather than pia and ependyma.

The appearance of the glial precursor cells at the edge of the ribbon (Fig. 11a) suggests that they may act in two ways to shepherd newly growing optic axons along the edge of the ribbon. Mechanically, the glial bridges formed during differentiation must resist forces to clasp the two surfaces of the ribbon together, as is evident at myelination (dashed line in Fig. 11a), where average fiber diameter increases 10 -fold, but with relatively little overall increase in overall ribbon thickness. In addition-possibly reflecting some cell-surface incompatibilitythe glial precursors are excluded from the extreme edge of the ribbon. The growth concs are thus presented with a narrow, preformed substrate of axonal wrists under the basal lamina, rather than with glia. This packed layer of wrists (Figs. 9-11), overlying finer unmyelinated fibers, may be specially equipped in some way as a substrate for growth cone guidance, accounting for the fast extension indicated by the counts in Figure 12.

Nonmyelin glia in the vertebrate CNS differentiate from early radial forms (tanycytes), expressing vimentin in the embryo, to terminally differentiated astrocytes, expressing GFAP in the 
adult, with stellate morphology and vascular endfeet. This transition is associatcd with the formation of the endoneurial capillary bed, and the changeover from vimentin to GFAP can occur quite late in mammalian development, for example, postnatally in the rat (Dahl et al., 1981). The ribbon optic nerve in fish lacks endoneurial capillaries and the glial network never achieves this developmental transition, retaining cmbryonic fcatures throughout adult life, namely, radial structure and vimentin-like IFs. Mammalian optic nerve astrocytes appear to be specialized along certain similar lines, with extremely fibrous cytoplasm (Vaughn and Pease, 1967), but proceed further into normal terminal astrocytic differentiation, acquiring stellate morphology postnatally (Dixon and Eng, 1981) and switching on GFAP as well as vimentin (Raff et al., 1984; Tsukita et al., 1981).

\section{Optic tract astroglia and nerve fiher growth}

The fish optic tract has conventional astrocytes, sharply different from those in the nerve. The differences relate principally to vascularization, since the tract has capillaries and the astrocytes form endfeet on them in the normal way. They also form an elaborate surface glia limitans, completely sealing optic fibers from the outside, and there appears to be no localized glial germinal zone like that at the edge of the ribbon. The tract astrocytes are GFAP-positive, band 3-negative, and protoplasmic in character, with very sparse IFs.

Astrocytic processes in the tract form a dense network of intertwined processes among new optic axons at the surface, but this array gets diluted as the fibers increase in size and acquire myelin, as can be seen below the dashed line in Figure $11 \mathrm{c}$. The result is that the mature astroglial network is sparse compared with that elsewhere in the CNS (compare Figs. $7 a$ and $8 a$ ), especially the optic nerve. We suspect that this may be necessary in order to interface the growing optic nerve with the tectum. Optic axons are added and rigidly stratified by quite different spatiotemporal programs of growth in the nerve and tectum (Raymond and Easter, 1983; Scholes, 1979), and the fiber array in the tract needs to deform gradually as the animal gets bigger, to accommodate this mismatch.

In the optic tract, growth cones spread out, contacting glia and axonal wrists indiscriminately (Fig. 11c). Our principal observation was that their numbers accumulate sharply (Fig. 12), suggesting that axonal extension is somehow hindered in the tract. Three possible factors could account for the 10 -fold difference observed. The velocity of growth cone extension could be slowed, changes in growth cone shape or complexity could increase sampling frequency in sections, and, finally, the axons could commence exploratory branching in the tract. These possibilities need evaluation by direct observations of labeled axons, but are likely to be interrelated. Thus, the shape and forward movements of growth cones are known to be substrate-dependent (Bray, 1982), and various factors impeding growth cone progress also favor branching (Shaw and Bray, 1977).

What glial properties could underlie the change in axonal growth behavior? One important difference is that growth cones have much more contact with glial surfaces in the tract than in the nerve (Fig. 10). This glial hospitality could impede growth cone extension, as can be seen in an intriguing parallel with the interactions between cerebellar glia and granule cells in vitro. Hatten ct al. (1984) showed that culturcd Bergman glia support granule cell migration. By contrast with these radial glia, which express vimentin in the adult (Bovolenta et al., 1984), conventional GFAP-positive cerebellar astroglia hold large numbers of granule cells immobile, trapped on their surfaces.

\section{Proposals regarding the optic chiasm and the monocular fiber-crossing}

The optic chiasm in most fish is unusual in that the optic nerves cross bodily, so that the optic tract boundary is located contra- lateral to the midline. In all vertebrate embryos, the chiasm initially develops where the optic stalks join the brain (cf., e.g., Silver, 1984), with fibers from the two eyes interweaving past one another at the midline (cf. Thanos and Bonhoeffer, 1984). This encounter with fibers from the opposite eye could be what presents the opportunity, in other animals, for decussation ipsilatcrally, thus forming the basis for binocular supcrimposition. The difference in fish is that, during extensive postembryonic growth, the boundary between optic nerve territory (band 3-positive glia) and the tract (GFAP-positive astrocytes) moves somewhat downstream towards the tectum, isolating the two nerves from one another where they cross the midline, and precluding further development of the interwoven chiasm found in other animals, like mammals, which rapidly complete growth in the embryo.

This encroachment of the optic nerve glial network contralaterally must result because the optic nerve astrocytes compete successfully with conventional (GFAP-positive) CNS astroglia at the tract boundary, thus advancing their frontier into what is normally brain tissue. This notion explains nicely how it comes about that the monocular retinotectal optic fiber-crossing is overtaken during differentiation by the band 3-positive glia of the optic nerve.

The optic nerve/tract boundary in fish separates two uniquely specialized glial compartments, which are less clearly defined in other vertebrates, in which vimentin and GFAP are both expressed in the optic nerve. We propose that fine evolutionary regulation of the boundary could be a sensitive way of determining what fraction of the optic pathway grows ipsilaterally during development. In the fish optic tract, axons encounter conditions that impede extension but favor exploration. Encountering similar conditions before the midline could make possible informed choice of which side of the brain to grow towards, and it may therefore be rewarding to characterize glial properties and fiber behavior at the chiasm in animals with an ipsilateral projection. In the chick, pioneer fiber trajectories are scarcely perturbed as they pass the chiasm (Thanos and Bonhoeffer, 1984), but here the adult visual pathway is entirely crossed.

Figure 2 shows that the tectal map is upright, that is, rotated through $180^{\circ}$ relative to the retinal image. This presumably has some importance for interfacing (cf. Calford et al., 1985) visual and other maps in the brain, and could, in principle, be mediated by an axial bodily twist through $180^{\circ}$ in the optic nerve. Instead the fish adopts the complicated alternative strategy of interweaving fibers through the monocular retinotectal fiber-crossing at the optic tract, as shown in Figure $2 b$. The embryonic neuroepithelium guiding early outgrowth of optic axons is a continuous surface, topologically incapable of forming the template for a completely twisted pathway (Scholes, 1981a). Bearing in mind this constraint, and the common orientation of the tectal map in all vertebrates, it follows rigorously that retinal fibers must generally criss-cross at some level en route to their destinations in the tectum, as well as negotiate various other distinct fiber reassortments known to occur at the chiasm (Walsh and Guillery, 1984).

In fish, the monocular fiber-crossing is the major step in reassorting optic fibers to match the tectal map, negotiated abruptly at the optic nerve/tract boundary. Because of distance from the tectum, it must be mediated by selective fasciculation with older fibers, in particular their axonal wrists, implying discrimination on some retinal positional basis. In Xenopus, ectopically located retinal fibers appear to be able to find like neighbors before arrival at the tectum (Fawcett and Gaze, 1982) and this selective behavior in the chick has been assayed directly by Bonhocffer and Huf (1985), using an elegantly devised Y-maze choice situation in vitro.

We suggest that the axonal response to the optic nerve/tract boundary in fish (Figs. $10 c$ and 11) allows growth cones to 
explore older fibers more extensively here than during passage through the ribbon optic nerve, enabling selective fasciculation. In this way, early choices made by pioneer fibers in the tectal rudiment of the embryo (cf. Holt, 1984) could propagate during subsequent growth in the adult, when localized where axons escape from the tight glial shepherding in the nerve. Details of the fiber patterns at this level (Fig. 1) may reveal something of the resolution with which retinal positional markers are expressed and discriminated by new axons during formation of the monocular fiber-crossing.

\section{References}

Ben Ze'ev, A. (1984) Differential control of cytokeratins and vimentin synthesis by cell-cell contact and cell spreading in cultured epithelial cells. J. Cell Biol. 99: 1424-1433.

Berry, M. (1979) Regeneration in the central nervous system. In Recent Advances in Neuropathology, No. 1, W. T. Smith and J. B. Cavanagh, eds., pp. 67-111, Churchill Livingstone, Edinburgh.

Bignami, A. (1984) Glial fibrillary acidic protein in Mueller glia. Immunofluorescence study of the goldfish retina. Brain Res. 300: 175178.

Bonhoeffer, F., and J. Huf (1985) In vitro experiments on positionally dependent properties of retinal axons and their growth cones. Nature 315: 409-410.

Bovolenta, P., R. K. Liem, and C. A. Mason (1984) Development of cerebellar astroglia: Transitions in form and cytoskeletal content. Dev. Biol. 102: 248-259.

Bray, D. (1982) Filopodial contraction and growth cone guidance. In Cell Behaviour, R. Bellairs, A. Curtis, and G. Dunn, eds., pp. 299317, Cambridge University Press, Cambridge.

Buerger, M. J. (1978) Elementary Crystallography, MIT Press, Cambridge, MA.

Bunt, S. M., and T. J. Horder (1977) A proposal regarding the significance of simple mechanical events, such as the development of the choroid fissure, in the organisation of central visual projections. J. Physiol. 272: 10-11P.

Burnette, W. N. (1981) Western blotting: Electrophoretic transfer of protein from SDS-polyacrylamide gels to unmodified nitrocellulose and radiographic detection with radioiodinated Protein $A$. Anal. Biochem. 112: 195-203.

Calford, M. B., M. L. Graydon, M. F. Huerta, J. H. Kaas, and J. D. Pettigrew (1985) A variant of the mammalian somatotopic map in a bat. Nature 313: 477-479.

Chiu, F.-C., B. Korey, and W. T. Norton (1980) Intermediate filaments from bovine, rat and human CNS: Mapping analysis of the major proteins. J. Neurochem. 34: 1149-1159.

Cleveland, D. W., S. G. Fischer, M. W. Kirschner, and U. Laemmli (1975) Peptide mapping by limited proteolysis in sodium dodecyl sulphate and analysis by gel electrophoresis. J. Biol. Chem. 252:11021106.

Dahl, D. (1981) The vimentin-GFA protein transition in rat neuroglia cytoskeleton occurs at the time of myelination. J. Neurosci. Res. 6 : 741-748.

Dahl, D., and A. Bignami (1973) Immunocytochemical and immunofluorescence studies of the glial fibrillary acidic protein in vertebrates. Brain Res. 61: 279-293.

Dahl, D., D. C. Rueger, A. Bignami, K. Weber, and M. Osborn (1981) Vimentin, the 57,000 molecular weight protein of fibroblast filaments, is the major cytoskeletal component of immature glia. Eur. J. Cell Biol. 24: 191-196.

Dixon, R. G., and L. F. Eng (1981) Glial fibrillary acidic protein in the optic nerve of the developing albino rat: An immunoperoxidase study of paraffin-embedded tissue. J. Comp. Neurol. 201: 15-24.

Dulbecco, R., R. Allen, S. Okada, and M. Bowman (1983) Functional changes of intemediate filaments in fibroblastic cells revealed by a monoclonal antibody. Proc. Natl. Acad. Sci. USA 80: 1915-1918.

Eng, L. F., and S. J. DeArmond (1982) Immunocytochemical studies of astrocytes in normal development and disease. Adv. Cell. Neurobiol. 3: 145-171.

Eng, L. F., J. J. Vanderhaegen, A. Bignami, and B. Gerstl (1971) An acidic protein isolated from fibrous astrocytes. Brain Res. 28: 351354.

Evans, R. M., and L. M. Fink (1982) An alteration in the phosphorylation of vimentin type intermediate filaments is associated with mitosis in cultured mammalian cells. Cell 29: 43-52.
Fawcett, J. W., and R. M. Gaze (1982) The retinotectal fibre pathways from normal and compound eyes in Xenopus. J. Emb. Exp. Morphol. 72: 19-37.

Franke, W. W., E. Schmid, M. Osborn, and K. Weber (1978) Different intermediate-sized filaments distinguished by immunofluorescence microscopy. Proc. Natl. Acad. Sci. USA 75: 5034-5038.

Franke, W. W., E. Schmid, S. Winter, M. Osborn, and K. Weber (1979) Widespread occurrence of intermediate-sized filaments of the vimentin-type in cultured cells from diverse sources. Exp. Cell Res. 123: $25-46$

Hatten, M. E., R. K. H. Liem, and C. A. Mason (1984) Two forms of cerebellar glial cells interact differently with neurones in vitro. J. Cell Biol. 98: 193-204.

Holt, C. E. (1984) Does timing of axon outgrowth influence initial retinotectal topography in Xenopus. J. Neurosci. 4: 1130-1152.

Hynes, R. O., and A. T. Destree (1978) $10 \mathrm{~nm}$ filaments in normal and transformed cells. Cell 13: 151-163.

Jackowski, A., and A. R. Lieberman (1979) Axonal growth cones of chick embryo retinal ganglion cells. J. Anat. 129: 866-869.

Jacobs, M., Q. L. Choo, and C. Thomas (1982) Vimentin and 70k neurofilament protein co-exist in embryonic neurons from spinal ganglia. J. Neurochem. 34: 969-977.

Kalil, K., and T. Reh (1979) Regrowth of severed axons in the neonatal central ncrvous system: Establishment of normal conncctions. Science 205: 1158-1161.

Laemmli, U. K. (1970) Cleavage of structural proteins during the assembly of the head of the bacteriophage T4. Nature 227: 680-685.

Lane, E. B., S. L. Goodman, and L. K. Trejdosiewicz (1982) Disruption of the keratin filament network during epithelial cell division. EMBO J. 1: 1365-1372.

Lane, E. B., B. L. M. Hogan, M. Kurkinen, and J. I. Garrels (1983) Co-expression of vimentin and cytokeratins in parietal endoderm cells of early mouse embryo. Nature 303: 701-704.

Lawson, D. (1983) Epinemin: A new protein associated with vimentin filaments in non-neural cells. J. Cell Biol. 97: 1891-1905.

Lazarides, E. (1982) Intermediate filaments: A chemically heterogeneous developmentally regulated class of proteins. Annu. Rev. Biochem. 51: 219-250.

Lubsen, J. (1921) Over de projectie het netvlies of het tectum opticum by een beenvisch. Ned. T. Geneesk. 67: 1258-1260.

Lund, R. D., P. W. Land, and J. Boles (1980) Normal and abnormal uncrossed retinotectal projections in rats: An HRP study in adults. J. Comp. Neurol. 189: 711-720.

Miller, R. H., and M. C. Raff (1984) Fibrous and protoplasmic astrocytes are biochemically and developmentally distinct. J. Neurosci. 4 585-592.

Nelson, W. J., and P. Traub (1982) Intermediate (10nm) filament proteins and the $\mathrm{Ca}$-activated proteinase specific for vimentin and desmin in the cells from fish to Man: An example of evolutionary conservation. J. Cell Sci. 57: 25-49.

Noble, M., J. Fok-Seang, and J. Cohen (1984) Glia are a unique substrate for the in vitro growth of central nervous system neurones. J. Neurosci. 4: 1892-1903.

Nordlander, R. H., and M. Singer (1982) Morphology and position of growth cones in the developing Xenopus spinal cord. Dev. Brain Res. 4: 181-193.

Peters, A., S. L. Palay, and H. de F. Webster (1976) The Fine Structure of the Nervous System: The Neurons and Supporting Cells, Saunders, Philadelphia, PA.

Presson, J., R. D. Fernald, and M. Max (1985) The organisation of retinal projections to the diencephalon and pretectum in the cichlid fish, Haplochromis burtoni. J. Comp. Neurol. 235: 360-374.

Pruss, R. (1979) Thy-1 antigen on astrocytes in long-term cultures of rat central nervous system. Nature 280: 688-690.

Pruss, R. M., R. Mirsky, M. C. Raff, R. Thorpe, A. J. Dowding, and B. H. Anderton (1981) All classes of intermediate filaments share a common antigenic determinant defined by a monoclonal antibody. Cell 27: 419-428.

Quitschke, W., and N. Schechter (1984) 58,000 Dalton intermediate filament proteins of neuronal and non-neuronal origin in the goldfish visual pathway. J. Neurochem. 42: 569-576.

Raff, M. C., E. R. Abney, J. Cohen, R. Lindsay, and M. Noble (1983) Two types of astrocytes in cultures of developing rat white matter: Differences in morphology, surface gangliosides and growth characteristics. J. Neurosci. 3: 1289-1300.

Raff, M. C., B. P. Williams, and R. H. Miller (1984) The in vitro 
differentiation of a bipotential glial progenitor cell. EMBO J. 3: 18571864

Rager, G. (1980) The development of the retinotectal projection in the chicken. Adv. Anat. Embryol. Cell Biol. 63: 1-92.

Rakic, P., and K. P. Riley (1983) Over-production and elimination of retinal axons in the fetal rhesus monkey. Science 219: 1441-1444.

Ramaekers, F. C. S., J. J. G. Putts, A. Kant, O. Moesker, P. H. K. Jap, and G. P. Vooijs (1981) Use of antibodies to intermediate filaments in the characterisation of human tumours. Cold Spring Harbor Symp. Quant. Biol. 46: 331-339.

Raymond, P. A., and S. S. Easter (1983) Post-embryonic growth of the optic tectum in goldfish. I. Location of germinal cells and numbers of ncurons produced. J. Ncurosci. 3: 1077-1091.

Reier, P. J., L. J. Stensaas, and L. Guth (1983) The astrocytic scar as an impedient to regeneration in the central nervous system. In Spinal Cord Reconstruction, C. C. Kao, R. P. Bunge, and P. J. Reier, eds., pp. 163-195, Raven, New York.

Rusoff, A. C. (1984) Paths of axons in the visual system of perciform fish and implications of these paths for rules governing axonal growth. J. Neurosci. 4: 1414-1428.

Rusoff, A. C., and S. S. Easter (1980) Order in the optic nerve of goldfish. Science 208: 311-312.

Schmid, E., M. Osborn, E. Rungger-Braendle, G. Gabbiani, K. Weber, and W. W. Franke (1982) Distribution of vimentin and desmin filaments in smooth muscle tissue of mammalian and avian aorta. Exp. Cell Res. 137: 329-340.

Schnitzer, J., W. W. Franke, and M. Schachner (1981) Immunocytochemical demonstration of vimentin in astrocytes and ependymal cells of developing and adult mouse nervous system. J. Cell Biol. 90: $435-447$.

Scholes, J. H. (1979) Nerve fibre topography in the retinal projection to the tectum. Nature 278: 620-624.

Scholes, J. H. (1981a) Ribbon nerves and axonal growth patterns in the retinal projection to the tectum. In Development in the Nervous System, J. Feldman and D. Garrod, eds., pp. 181-214, Cambridge University Press, Cambridge.

Scholes, J. H. (1981b) Retinal fibre patterns in the primary visual pathways to the brain. In Sense Organs, M. S. Laverack and D. Cosens, eds., pp. 255-275, Blackie, Edinburgh.

Schwassmann, H. O. (1975) Central projections of the retina and vision. In Vision in Fishes, M. A. Ali, ed., pp. 113-126, Plenum, New York.

Shaw, G., and D. Bray (1977) Movement and extension of isolated growth cones. Exp. Cell Res. 104: 55-62.

Shaw, G., and K. Weber (1983) The structure and development of the rat retina: An immunofluorescence study using antibodies specific for intermediate filaments. Eur. J. Cell Biol. 30: 219-232.
Shaw, G.. M. Osborn, and K. Weber (1981) An immunofluorescence study of the NF triplet proteins, vitamin and glial fibrillary acidic protein within the adult rat brain. Eur. J. Cell Biol. 26: 68-82.

Silver, J. (1984) Studies on the factors that govern the directionality of axonal growth in the embryonic optic nerve and at the chiasm of mice. J. Comp. Neurol. 223: 238-251.

Silver, J., and U. Rutishauser (1984) Guidance of optic axons in vivo by a pre-formed adhesive pathway on neuro-epithelial end-feet. Dev. Biol. 106: 485-499.

Singer, M., R. H. Nordlander, and M. Egar (1979) Axonal guidance during embryogenesis and regeneration in the spinal cord of newt. The blue-print hypothesis of neuronal pathway patterning. J. Comp. Neurol. 185: 1-22.

Sperry, R. W. (1943) Effect of $180^{\circ}$ rotation of the retinal field on visuomotor coordination. J. Exp. Zool. 92: 263-279.

Sperry, R. W. (1963) Chemoaffinity in the orderly growth of nerve fibre patterns and connections. Proc. Natl. Acad. Sci. USA 50: 703709.

Stuermer, C. A. O., and S. S. Easter (1984) Rules of order in the retinotectal fascicles of goldfish. J. Neurosci. 4: 1045-1051.

Tapscott, S. J., G. S. Bennett, Y. Toyama, F. Kleinbart, and H. Holtzer (1981) Intermediate filament proteins in developing chick spinal cord. Dev. Biol. 86: 40-54.

Thanos, S., and F. Bonhoeffer (1984) Development of the transient ipsilateral projection in the chick embryo: A numerical fluorescencemicroscopic analysis. J. Comp. Neurol. 224: 407-414.

Torrealba, F., R. W. Guillery, U. Eysel, E. H. Polley, and C. A. Mason (1982) Studies of retinal representations within the cat's optic tract. J. Comp. Neurol. 211: 377-396.

Towbin, H., T. Staehelin, and J. Gordon (1979) Electrophoretic transfer of proteins from polyacrylamide gels to nitrocellulose sheets: Procedure and some applications. Proc. Natl. Acad. Sci. USA 76: 43504354.

Tsukita, S., H. Ishikawa, and M. Kurokawa (1981) Isolation of $10 \mathrm{~nm}$ filaments from astrocytes in the mouse optic nerve. J. Cell Biol. 88 : 245-250.

Vaughn, J. E., and D. C. Pease (1967) Electron microscopy of classically stained astrocytes. J. Comp. Neurol. 131: 143-153.

Virtanen, I., V.-P. Lehto, E. Lehtonen, T. Vartio, S. Stenman, P. Kurki, O. Wager, J. V. Small, D. Dahl, and R. A. Badley (1981) Expression of intermediate filaments in cultured cells. J. Cell Sci. 50:45-63.

Walsh, C., and R. W. Guillery (1984) Fibre order in the pathways from the eye to the brain. Trends Neurosci. 7: 208-211.

Yen, S.-H., and K. L. Fields (1981) Antibodies to neurofilament, glial filament and fibroblast intermediate filament protein bind to different cell types in the nervous system. J. Cell Biol. 88: 115-126. 